This item was submitted to Loughborough's Research Repository by the author.

Items in Figshare are protected by copyright, with all rights reserved, unless otherwise indicated.

\title{
Dynamic verification of a multi-body computational model of human head and neck for frontal, lateral, and rear impacts
}

PLEASE CITE THE PUBLISHED VERSION

\section{PUBLISHER}

(C) Professional Engineering Publishing

\section{VERSION}

VoR (Version of Record)

\section{LICENCE}

CC BY-NC-ND 4.0

\section{REPOSITORY RECORD}

van Lopik, David W., and Memis Acar. 2019. "Dynamic Verification of a Multi-body Computational Model of Human Head and Neck for Frontal, Lateral, and Rear Impacts". figshare. https://hdl.handle.net/2134/4534. 
This item was submitted to Loughborough's Institutional Repository (https://dspace.lboro.ac.uk/) by the author and is made available under the following Creative Commons Licence conditions.

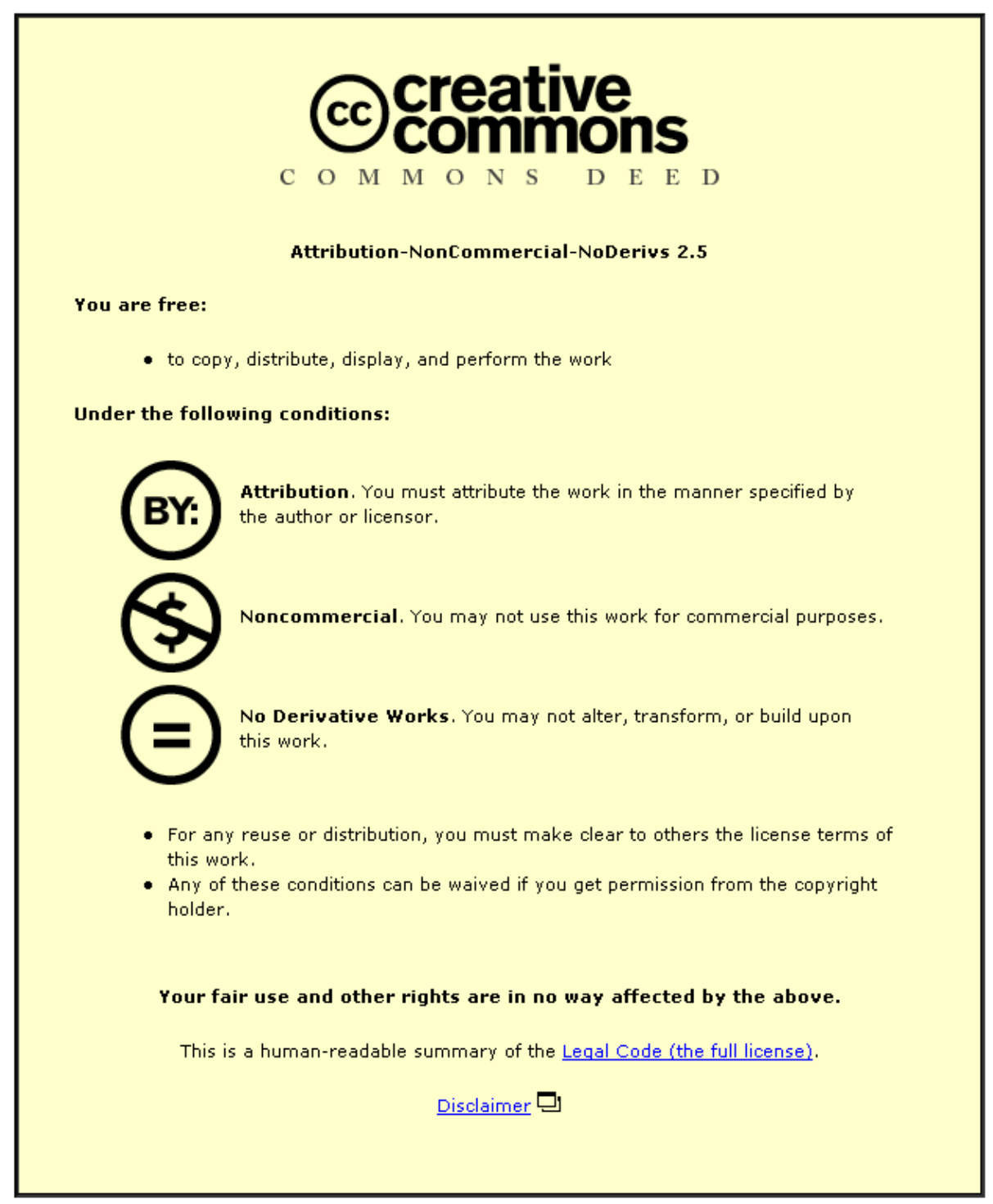

For the full text of this licence, please go to: http://creativecommons.org/licenses/by-nc-nd/2.5/ 


\title{
Dynamic verification of a multi-body computational model of human head and neck for frontal, lateral, and rear impacts
}

\author{
D W van Lopik and M Acar* \\ Mechanical and Manufacturing Engineering, Loughborough University, Loughborough, UK \\ The manuscript was received on 31 July 2006 and was accepted after revision for publication on 30 January 2007.
}

DOI: 10.1243/14644193JMBD89

\begin{abstract}
A multi-body computational model of the human head and neck was previously shown to be in good agreement with experimental findings from actual human cervical spine specimens. The model segments were tested in three directions of loading showing main and coupled motions to be accurate and realistic.

The model's ability to predict the dynamic response of the head and neck, when subjected to acceleration pulses representing frontal, lateral, and rear-end impacts, is verified using experimental data derived from sled acceleration tests with human volunteers for $15 \mathrm{~g}$ frontal and $7 \mathrm{~g}$ lateral impacts and from isolated cervical spine specimen tests for rear-end impacts. Response corridors based on sled acceleration tests with human volunteers for frontal and lateral impacts are used to evaluate the model and investigate the effect of muscle activation on the headneck motion. Firstly, the impacts are simulated with both passive and active muscle behaviour. Secondly, the local loads in the soft-tissue elements during the frontal impact are analysed. For rear-end impact simulation experiments using ligamentous isolated cervical spine specimens are used to evaluate the model performance before investigating the effects of muscle tensioning.

Good agreement with human volunteer response corridors resulting from frontal and lateral impacts, and isolated cervical spine specimen sled test rear-end impact experiments is demonstrated for the model, highlighting the important role the muscles of the neck play in the head-neck response to acceleration impacts. The model is shown to be able to predict the loads and deformations of the cervical spine components making it suitable for injury analysis.
\end{abstract}

Keywords: cervical spine, head and neck, multi-body computational model, vertebrae, ligament forces, muscle forces

\section{INTRODUCTION}

A whiplash injury is therefore an injury to soft tissue, i.e. to one or more of the many ligaments, intervertebral discs, facet joints, or muscles of the neck. Many different possible mechanisms for whiplash injuries have been proposed but no definitive explanation has yet been established. Whiplash injury is a frequent consequence of automobile accidents and has been a significant

\footnotetext{
* Corresponding author: School of Mechanical and Manufacturing Engineering, Loughborough University, Loughborough LE11 3TU, UK.email:m.acar@lboro.ac.uk
}

public health and socio-economic problem on the increase.

Experimental studies using human volunteers are limited to low acceleration impacts while whole cadavers, isolated cervical spine specimens, and impact dummies do not normally reflect the true human response. Computational modelling offers a cost effective and useful alternative to experimental methods to study the behaviour of the human head and neck and their response to impacts to gain insight into injury mechanisms.

A detailed multi-body computational model that reproduces the head and cervical spine of an adult in the upright posture representing the natural lordosis of the neck with midsagittal symmetry was reported [1]. The model comprises simplified but 
accurate representations of the nine rigid bodies representing the head, seven cervical vertebrae of the neck, and the first thoracic vertebra. The rigid bodies are interconnected by non-linear viscoelastic intervertebral discs elements in flexion and extension, non-linear viscoelastic ligaments, and supported through frictionless facet joints. Eighteen muscle groups and 69 individual muscle segments of the head and neck on each side of the body are also included in the model. Curving the muscle around the vertebrae and soft tissues of the neck during the motion of the neck is also modelled. Simulation is handled by the multi-body dynamic software visualNastran4D. Muscle mechanics is handled by an external application, virtual muscle, in conjunction with MSC.visualNastran4D, that provides realistic muscle properties, as detailed in [1].

Simulation is handled by the multi-body dynamic software MSC.visualNastran4D. visualNastran4D uses constraint force algorithms for solving the dynamics equations of motion [3]. Although the applied forces are known, the magnitude and/or direction of the constraint forces must be determined through the application of a dynamic principle. The advantages of the constraint algorithms over other equations of motion are that they simulate systems with varying degrees of freedom including static and coulomb friction; handle collisions; allow users to specify various motion through length, velocity, and acceleration actuators; and deal with inequality constraints such as rope and separators. The constraint force algorithm is a variation of the well-known Newton-Euler equations of motion, which can be written as

$$
\begin{aligned}
\boldsymbol{F} & =m a \\
T & =I \alpha+\omega \times I \omega
\end{aligned}
$$

Newton-Euler 'free-body' method leads to a large set of equations whose unknowns are the constraint forces and accelerations. The constraint force algorithm breaks the problem into two parts. First, it uses linear algebra techniques to isolate and solve a relatively small set of equations for the constraint forces only. Then, with all the forces on each body known, it solves for the accelerations, without solving any additional linear equations. This leads to substantial computational savings.

The cervical spine motion segments were validated by comparing the segment response with published experimental data on the load-displacement behaviour for both small and large static loads. The response of the entire ligamentous cervical spine model to quasi-static flexion and extension loading was also compared with experimental data to validate the model before the effect of muscle stiffening is included. Moreover, the moment-generating capacity of the neck muscle elements was compared against in vivo experimental data.

The main and coupled motions of the model segments were shown to be accurate and realistic and the whole model is in good agreement with experimental findings from the actual human cervical spine specimens. It was shown that the model can predict the loads and deformations of the individual soft-tissue elements making the model suitable for injury analysis. The validation of the muscle elements showed the morphometric values, origins, and insertions selected to be reasonable. The muscles can be activated as required, provide a more realistic representation of the human head and neck. The curved musculature results in a more realistic representation of the change in muscle length during the head and neck motion.

Previously published multi-body models of the head and neck were reviewed in reference [1]. The improvements of the present model are in the detailed representation of the cervical vertebrae, the more accurate properties of the soft tissues and in the complexity of the muscle elements. More details of the geometry of the vertebrae was included in this model than seen in other multi-body models allowing for more accurate location of muscle and ligament attachment sites. Also the geometry was based on mean data from experimental measurements of human vertebrae as opposed to direct measurements from a single spine specimen, hence this method will give a more general representation of an average adult human neck.

The specific aim of this paper is to validate the dynamic behaviour of the detailed multi-body model using volunteer and cadaver test results. This model is intended to be used in simulating crash scenarios in frontal, lateral, and rear impacts, and provide an economical tool to estimate the severity of effect on the human head and neck and estimate injury risks.

\section{METHOD}

To validate the model it is important to check its ability to predict the dynamic response of the head and neck when subjected to acceleration pulses representing frontal, lateral, and rear-end impacts. Response corridors based on sled acceleration tests with human volunteers are used to evaluate the model for frontal and lateral impacts. The corridors specify the response that a valid model of the human head and neck should meet. For rear-end impact, experiments using isolated cervical spine specimens on a bench-top trauma sled are used to validate the model.

The response corridors used to validate the model for frontal and lateral impact were produced from sled acceleration tests with human volunteers performed at the Naval Biodynamics Laboratory (NBDL). These 
corridors have also been used by other researchers to validate mathematical and mechanical models of the head and neck [4-10]. Male human volunteers were seated in an upright position on a sled driven HYGE accelerator and exposed to short duration accelerations simulating $15 \mathrm{~g}$ frontal and $7 \mathrm{~g}$ lateral impacts. The resulting three-dimensional motions of the head and first thoracic vertebral body (T1) were monitored. Wismans et al. [11] presented results of the NBDL tests for frontal and lateral impacts while a new analysis of the most severe frontal impacts was made later by Thunnissen et al. [9]. The original data are used to validate the models response to lateral impact while the response corridors presented by Thunnissen $\mathrm{et} \mathrm{al}$. [9] are used to validate the models response to frontal impact.

For rear-end impact a series of experiments performed by Panjabi et al. [12-14] and Grauer et al. [15] using a bench-top trauma sled to simulate whiplash trauma on human cadaveric cervical spine specimens are used to validate the head-neck model. These studies used cadaveric cervical spine specimens stripped of all non-ligamentous soft tissues mounted to a bench-top sled device where an acceleration pulse was applied to the base of the specimen to reproduce whiplash trauma. These tests are an alternative to experiments using volunteers, whole body cadavers or anthropometrical crash dummies and have been shown to effectively simulate whiplash trauma and have provided valuable insights into the complex events and interactions that cause injuries to the cervical spine. In simulating these experiments the model is used without musculature with an acceleration pulse applied to T1. Varying levels of impact severity are simulated. A qualitative comparison of the resulting head-neck motion to that described in the literature is presented as well as a quantitative comparison of head motion and maximum vertebral rotations. An analysis of the internal loads of the soft-tissue components for the most severe impact simulated has been completed to identify possible areas of injury. Finally, the muscles are added back to the model to study their effect on the head-neck motion in response to rear-end impact and on the internal forces developed in the neck. The effects of both passive and active musculature are investigated.

\subsection{Frontal and lateral impacts}

In both frontal and lateral impact simulations, the average $\mathrm{T} 1$ acceleration and rotation from the human volunteer tests are used as inputs to the head-neck model (Fig. 1). Motion of the T1 vertebrae was limited
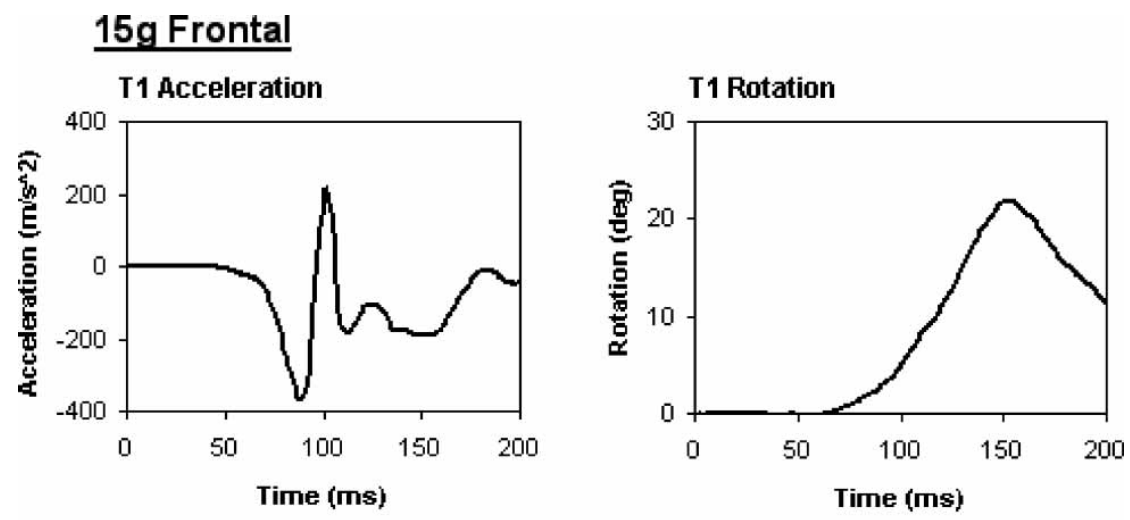

\section{$\underline{7 g}$ Lateral}
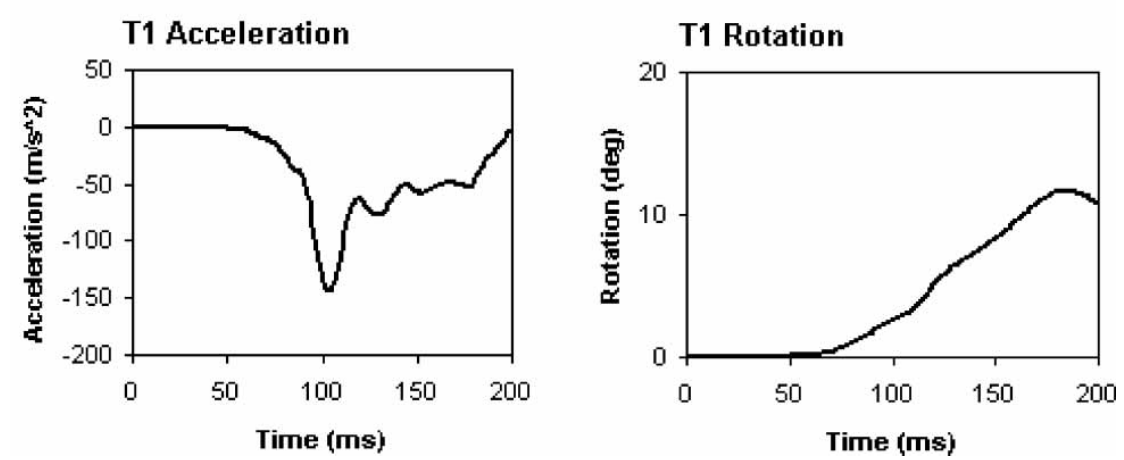

Fig. 1 Average T1 accelerations and rotations used as input to the head-neck model to simulate frontal and lateral impacts 
to the direction of impact while the rest of the model was left free to move in all directions. For frontal impact simulation T1 was accelerated in the $x$-axis and rotated about the $y$-axis while for lateral impact T1 was accelerated along the $y$-axis and rotated about the $x$-axis. For all other directions motion was found to be negligible in the analysis of the volunteer results $[10,11]$.

Recent research indicates that the role of the muscles in limiting head-neck motion during impact may be significant. Siegmund and Brault [16] state that the cervical muscles can be activated early enough and are capable of altering the head and neck kinematics during impact trauma. It is conceivable that muscle contraction may have taken place in the experiments on the human volunteers at the NBDL and so experiments with active and passive musculature are simulated and compared with the response corridors. Cervical muscle contraction during trauma is thought to be a reflex response but the pathways mediating the response are unclear. During an impact there is a rapid sequence of events that may lead to the muscle reflex such as a loud noise on impact, vehicle motion, and vibration, and induced whole-body motion. The reflex time, the time between stimulus and muscle activation, has been shown to be anywhere between 60 and $175 \mathrm{~ms}$ for cervical spine muscles [16]. Hence an initial reflex response time of $75 \mathrm{~ms}$ within this bracket has been selected for frontal and lateral impact simulations. All muscles are activated 100 per cent together, after the $75 \mathrm{~ms}$ reflex time, for two reasons: (a) exact activation levels for the cases simulated are not known and (b) it is assumed that in the event of an accident, because of the small time frame, one would brace their muscles as much as possible, like a reflex action.

\subsection{Rear-end impacts}

To simulate the bench-top sled tests all muscles were removed from the head-neck model. The motion of T1 was constrained so only translation along the $x$-axis was possible. The acceleration input for the spine specimen experiments was a triangular pulse with duration of $105 \mathrm{~ms}$ to represent whiplash trauma. Peak accelerations of $2.5 \mathrm{~g}$, $4.5 \mathrm{~g} .6 .5 \mathrm{~g}$, and $8.5 \mathrm{~g}(\mathrm{~g}=$ $9.8 \mathrm{~m} / \mathrm{s}^{2}$ ) were studied [15]. Unfortunately the actual acceleration profiles used in the experiments are not presented, so idealized acceleration profiles are used as input to the model as described by Raynak and Ching [17]. The profiles are triangular with the same $105 \mathrm{~ms}$ duration and corresponding peak accelerations (Fig. 2). The resulting head rotations and translations are compared against the results for the $8.5 \mathrm{~g}$ trauma class and the maximum vertebral rotations are compared at all levels.

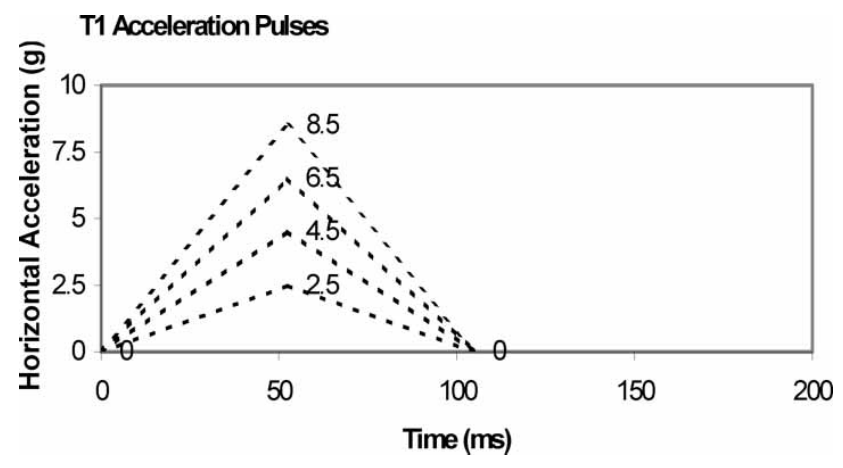

Fig. 2 Horizontal T1 acceleration profiles used as input to the head-neck model for the four classes of impact trauma, 2.5-8.5 $g$

To study the effect of muscle tensioning on the head-neck response to rear-end acceleration trauma the model with all muscles in place was set-up as described above. The same acceleration pulse was used as input to $\mathrm{T} 1$ to simulate the $8.5 \mathrm{~g}$ sled test with the onset of the acceleration delayed by $50 \mathrm{~ms}$. For active muscle response the onset time of muscle activation was set at $75 \mathrm{~ms}$ after the start of the simulation, $25 \mathrm{~ms}$ after the onset of $\mathrm{T} 1$ acceleration, at which point all muscles were given 100 per cent activation. For the passive response, the activation level of all muscles was left at zero for the duration of the simulation. The response of the active and passive model can be assumed to represent an initially relaxed occupant with and without muscle response.

To demonstrate the head-neck model's ability to predict the local loading of the soft-tissue components a detailed analysis of the individual component loads over the $200 \mathrm{~ms}$ frontal impact has been performed. The case with muscle activation has been used as this was shown to give best agreement with the volunteer response corridors. The loads in the ligaments of the upper and lower cervical spine are presented, followed by the force and moments in the intervertebral discs. Finally, the forces developed in the active muscle elements are studied.

\section{SIMULATION RESULTS}

\subsection{Frontal impact simulation}

Figure 3 depicts the overall head-neck model response with active musculature over the first $200 \mathrm{~ms}$ of the $15 \mathrm{~g}$ frontal impact. Muscle reflex time was set to $75 \mathrm{~ms}$. Over the initial stages of impact $(<100 \mathrm{~ms})$ as the neck is rotating forward the head translates forward with respect to $\mathrm{Tl}$ with very little rotation. Following $100 \mathrm{~ms}$ up to around $160 \mathrm{~ms}$, where maximum forward flexion is reached, the head and neck rotate together. After the point of maximum flexion 

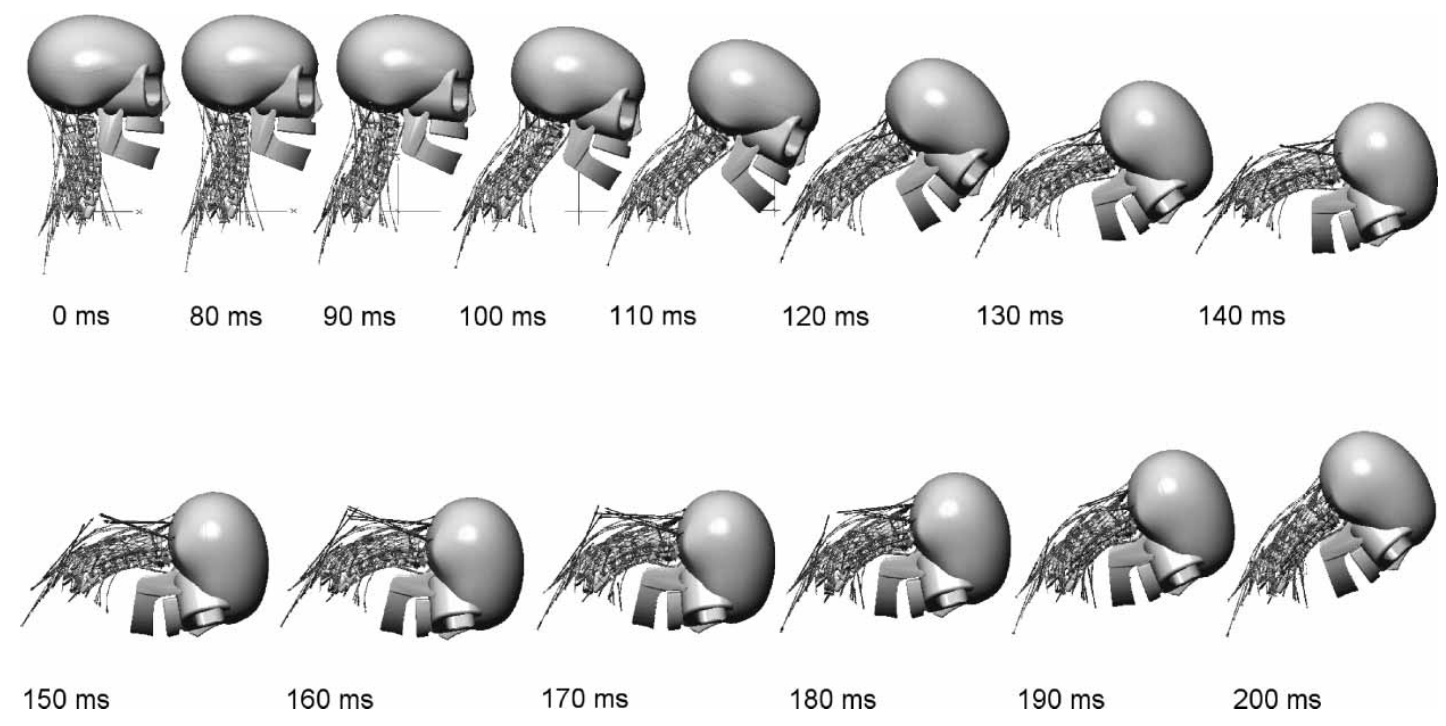

Fig. 3 Time history of the head-neck model response to $15 \mathrm{~g}$ frontal impact with 100 per cent active musculature

the head and neck begin to rebound towards the initial position. Muscle force vectors are shown and it can be seen how force is developed in the extensor muscles as the head is thrown forward then on rebound the flexor muscles of the neck try to resist the return motion of the head.

The model is compared to the NBDL volunteer response corridors for both active and passive muscle behaviour to see the effect muscles forces have on the overall response of the model. The resultant accelerations of the head are shown in Figs 4(a) and (b) along with the trajectories of the occiput and centre of gravity of the head, Figs 4(c) and (d). The linear and angular accelerations of the head with active muscles differ only slightly from the passive response and both are in reasonable agreement with response corridors. The drop in linear acceleration around $110 \mathrm{~ms}$ is too great in the model compared to that experienced by the human volunteers and the peak angular accelerations of the head appear slightly too weak. The trajectories of the occipital condyles and the head centre of gravity fall well within the corridors for active muscle response; with passive properties the head displacement is greater in the horizontal direction. Figures 5(a) to (d) show the head and neck rotation, neck length, and head lag of the model compared to the response corridors of the NBDL volunteers. Neck rotation agrees well with the corridor for the first $110 \mathrm{~ms}$, after which rotation becomes too large and exceeds the corridors slightly, maximum rotation of the neck is reached at $160 \mathrm{~ms}$ around $15 \mathrm{~ms}$ earlier than the volunteers. Muscle activation plays only a small role in reducing the maximum rotation of the neck. Head rotation of the model with active and passive muscle behaviour agrees well with the corridor for the first $140 \mathrm{~ms}$ after which head rotation of the passive model becomes too great, the resistive force developed by the active muscles prevent the head rotation from exceeding the corridors. The effect of active muscle contraction can also be clearly seen in the graph showing change in neck length with time (Fig. 5(c)). With passive muscles the length of the neck increases beyond the corridor but with the stiffening effect of the active muscles the model response falls well within the corridor. The length of the neck starts to return towards its starting length sooner than was seen with the volunteers. Figure 5(d) shows the neck angle versus the head angle showing how the flexion of the head lags behind the rotation of the neck link for both passive and active muscle simulation during the initial stages of impact. Practically, no head rotation was experienced by the volunteers for the first $100 \mathrm{~ms}$ of impact, whereas the model shows around $5^{\circ}$ of forward flexion. After the neck link reaches around $35^{\circ}$, both the head and neck rotate together and follow the volunteer corridor closely. Towards the end of the impact, head rotation of the passive model begins to exceed the rotation of the neck link as the model begins to rebound.

\subsection{Lateral impact simulation}

The time history of the model's response with active musculature over the first $200 \mathrm{~ms}$ of the $7 \mathrm{~g}$ lateral impact is shown in Fig. 6. During the first $110 \mathrm{~ms}$ of the impact the head translates laterally in the $y$-axis with only a small amount of rotation. Following this, significant rotation of the head develops about the $x$-axis and from around $120 \mathrm{~ms}$ the head also begins to twist about the $z$-axis. Substantial muscle forces are developed in the muscles on the left side of the neck between 130 and $180 \mathrm{~ms}$ to oppose the motion of the head as it is thrown sideways. 
a) Head CG Resultant Linear Acceleration

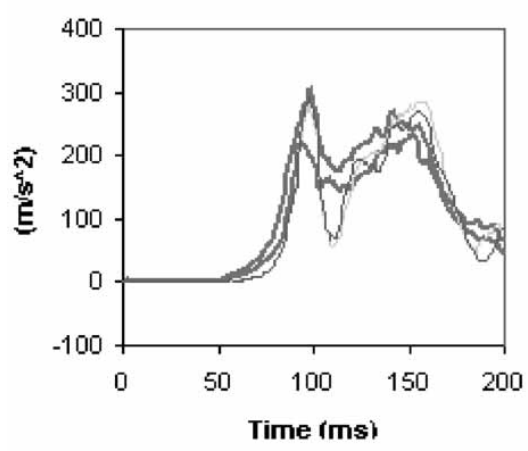

c) Occiput Trajectory

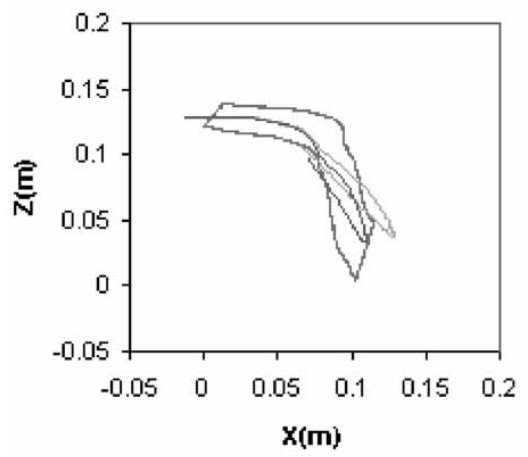

b) Head CG Angular Acceleration

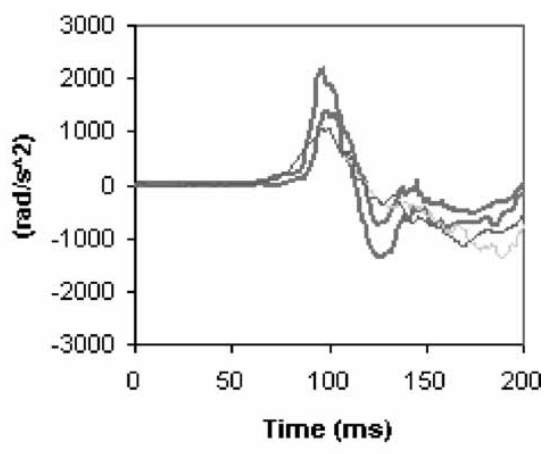

d) CG Trajectory

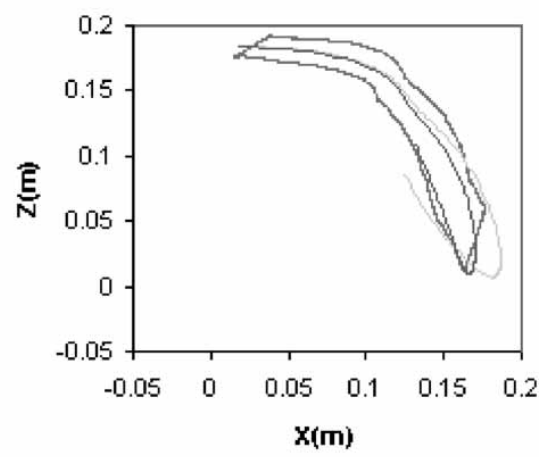

HBDL Volunteer Response Corridor

Model Response- Passive Muscles

Model Response- Active Muscles

Fig. 4 Head-neck model response to $15 \mathrm{~g}$ frontal impact with passive and active muscle behaviour compared against NBDL volunteer response corridors

The model is compared with the NBDL volunteer response corridors for both active and passive muscle behaviour to see the effect muscle forces have on the overall response of the model and how well the model predicts the head-neck motion. The three components of linear acceleration of the head centre of gravity are shown in Figs 7(a) to (c). The linear acceleration of the head in the $x$-direction is in excellent agreement with the response corridors of the model with active muscle behaviour; with passive properties acceleration is developed slightly later than the corridors. In the $y$-direction acceleration increases a little too early for the model with both active and passive muscles; however, the active response generally agrees well with the corridors after around $120 \mathrm{~ms}$. In the $z$-direction the acceleration of the model is smaller compared with the volunteer corridors, however, the general shape of the active response follows that of the corridors. The trajectories of the occipital condyles and the head centre of gravity are compared against the volunteer response corridors in Fig. 7(d). The active response follows the corridors well but eventually exceeds them as the head rotates too far. The model response with passive muscles shows too much displacement in the $y$-direction, deviating from the corridors earlier than seen with the active response, and with the downward displacement exceeding both the volunteer corridors and that of the active model. The angular acceleration of the head about the $x$ - and $z$-axis is shown in Figs 8(a) and (b) showing reasonable agreement between the active model and the response corridors.

A fairly similar response is seen between active and passive model for the $x$-angular acceleration. With passive muscle properties the model's angular acceleration about the $z$-axis is similar up to around $140 \mathrm{~ms}$. Following which smaller acceleration is experienced in comparison with the corridors and that of the active model. The strong effect of muscle tensioning can be seen in Fig. 8(c) on the rotation of the head about the $x$-axis. Although the model with both active and passive muscle properties eventually exceeds the volunteer corridors, it can be seen how the active muscle properties substantially limit the degree of lateral bending of the head. Similarly, better agreement with the corridors can be seen for 
a) Heck Rotation

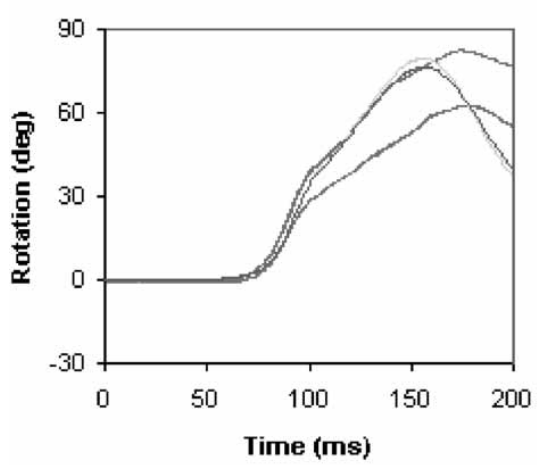

c) Neck Length

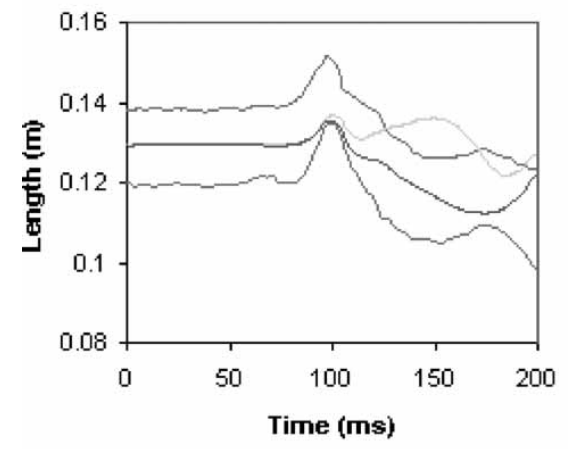

b) Head Rotation

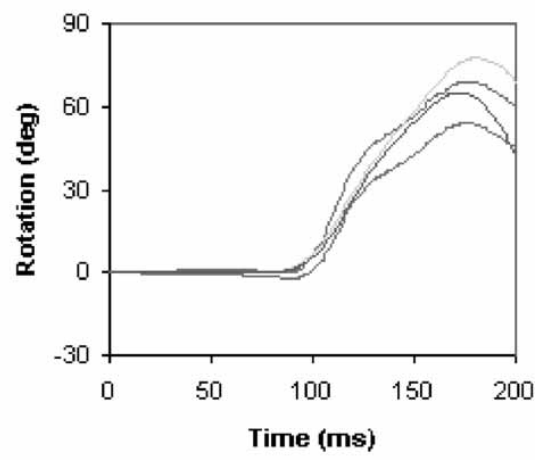

d) Head Lag

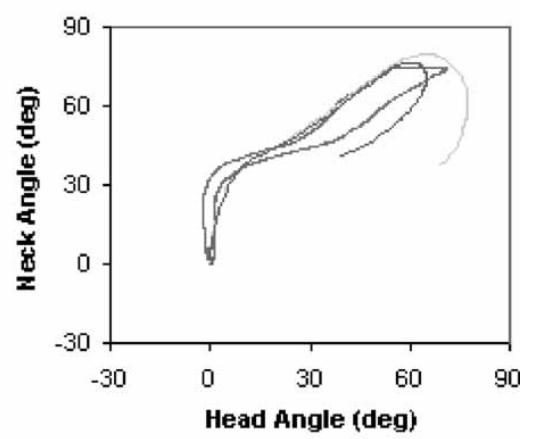

HBDL Volunteer Response Corridor

Model Response- Passive Muscles

Model Response- Active Muscles

Fig. 5 Head-neck model response to $15 \mathrm{~g}$ frontal impact with passive and active muscle behaviour compared against NBDL volunteer response corridors

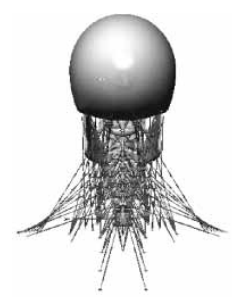

$0 \mathrm{~ms}$

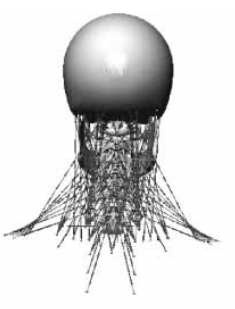

$100 \mathrm{~ms}$

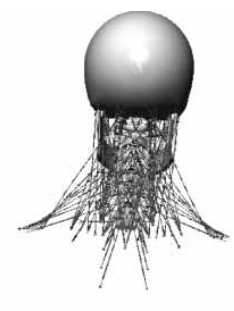

$110 \mathrm{~ms}$

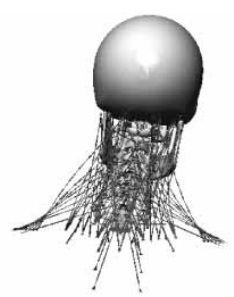

$120 \mathrm{~ms}$

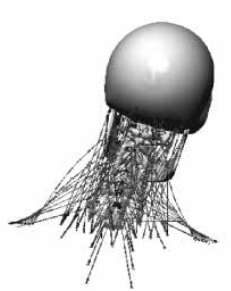

$130 \mathrm{~ms}$

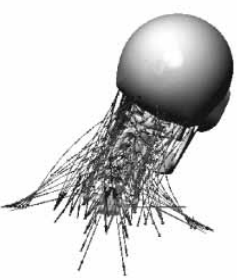

$140 \mathrm{~ms}$

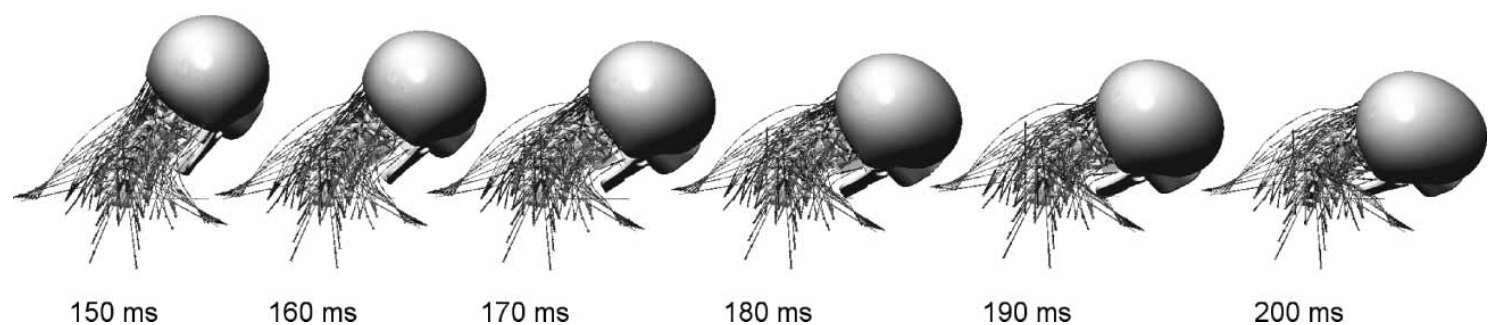

Fig. 6 Time history of the head-neck model response to $15 \mathrm{~g}$ frontal impact with 100 per cent active musculature

the model with active musculature for rotation of the head about the $z$-axis (Fig. 8(d)) showing the muscle forces to increase the axial rotation earlier compared to the model with passive properties. The peak axial rotation for the model with active properties occurs at around $180 \mathrm{~ms}$, which is in agreement with the 
a) X-Angular Acceleration

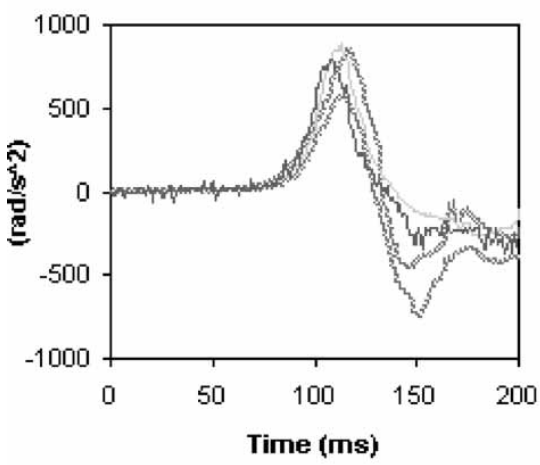

c) Head X-Rotation

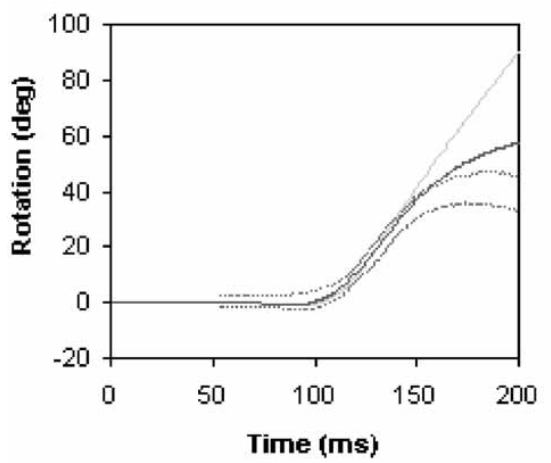

b) Z-Angular Acceleration

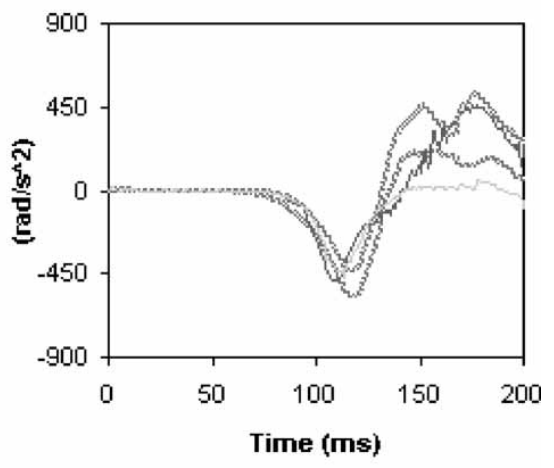

d) Head Z-Rotation

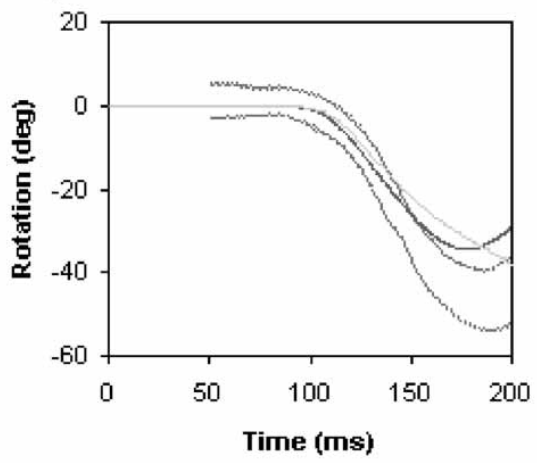

HBDL Volunteer Response Corridor

Model Response- Passive Muscles

Model Response- Active Muscles

Fig. 7 Head-neck model response to $7 g$ lateral impact with passive and active muscle behaviour compared against NBDL volunteer response corridors

volunteer response. However, the magnitude of the rotation is slightly less than the corridors.

\section{COMPONENT LOADING FOR FRONTAL IMPACT}

\subsection{Ligament forces}

Figure 9 shows the forces developed in the ligaments of the lower cervical spine; for clarity the ligaments are split further into mid- (C2-C5) and lower- (C5-T1) cervical spine levels. It can be seen how for the majority of the ligaments maximum force occurs at around $100 \mathrm{~ms}$, corresponding to the time of maximum head acceleration and maximum neck excursion. Significant forces are developed in the majority of ligaments of the midcervical level because of the tensile loading of the neck as the head is thrown forward. Little force is developed in the anterior longitudinal ligaments of the lower levels, as flexion of the lower vertebrae is dominant early in the impact. Consequently, all the posterior ligaments of the lower levels develop large loads, in most cases larger than their equivalent ligaments of the midlevels. The loads in the posterior ligaments (FL, CL, ISL) of C2-C3 are small in the early stages of impact due to this segment being forced into extension. As the neck rotates further and flexion is developed at all levels of the lower cervical spine the tension in the anterior longitudinal ligaments is relieved whereas the posterior ligaments become more and more strained. A second general peak in ligament force can be seen around 150-160 ms as maximum forward flexion of the neck is reached. The capsular ligaments of the lowest segment C7-T1 appear to be loaded significantly more than at other levels; this is thought to be because of the orientation of the facets at this level.

A similar peak in force can be seen for the ligaments of the upper cervical spine at around $100 \mathrm{~ms}$ (Fig. 10) although no force is developed in the posterior membranes as both joints are forced into extension because of the lagging of the head rotation behind neck rotation (head lag, Fig. 5(d)). Extremely large forces are developed in the alar and transverse ligaments demonstrating their important role in stiffening the upper segments in the absence of 
a) X-Linear Acceleration

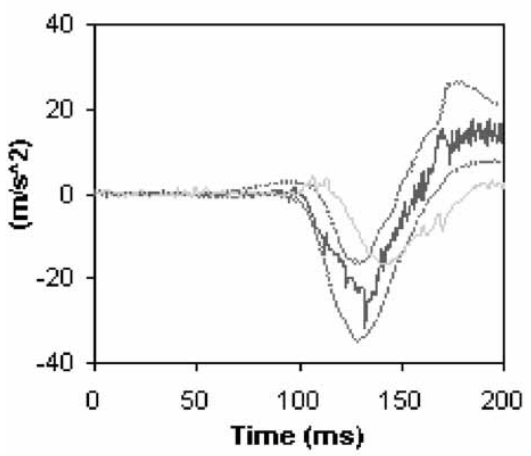

c) Z-Linear Acceleration

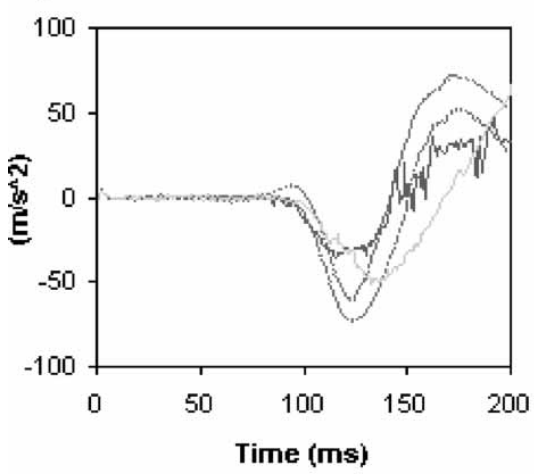

b) Y-Linear Acceleration

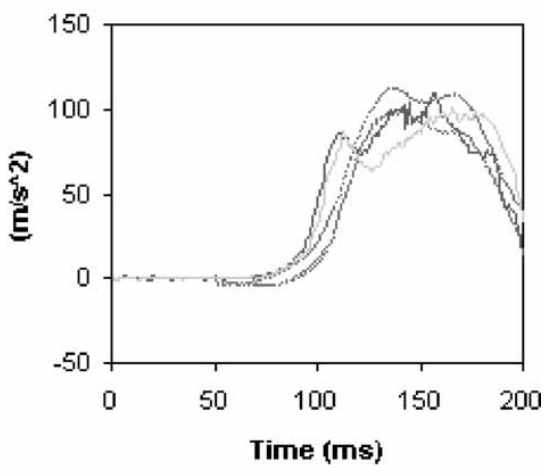

d) OC and CG Trajectory

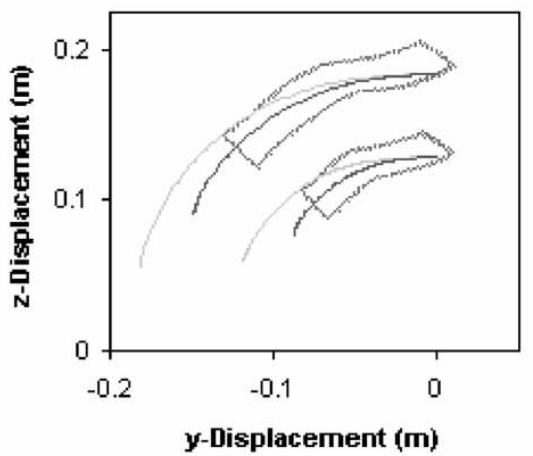

HBDL Volunteer Response Corridor

Model Response- Passive Muscles

Model Response- Active Muscles

Fig. 8 Head-neck model response to $7 \mathrm{~g}$ lateral impact with passive and active muscle behaviour compared against NBDL volunteer response corridors

intervertebral discs. Towards the end of the impact duration, as the head is returning towards its initial position, force is developed in the posterior membrane of $\mathrm{C} 1-\mathrm{C} 2$ as this joint changes from extension to flexion, as would be expected tension in the anterior membrane tails off at this point.

\subsection{Intervertebral disc forces and moments}

Figure 11 shows the forces and moments experienced by the intervertebral discs in frontal impact over the course of the $200 \mathrm{~ms}$ impact. Because of the nature of a direct frontal impact no forces were developed in lateral shear and moments were experienced about the $y$-axis only. A peak in anterior shear and tension of the discs at all levels can be seen at around $100 \mathrm{~ms}$ at maximum neck excursion. In the early stages of impact anterior shear is the dominant force of the C7T1 disc. Following maximum neck excursion, compression in the discs develops reaching a maximum at all levels at around 180-190 ms. This can be attributed to the limiting effect of the muscles on the level of neck lengthening after the initial tension in the discs as the head is thrown forward compressing the discs. Torque in the discs increases with flexion of the vertebrae and reaches a maximum at all levels at around $160 \mathrm{~ms}$ in conjunction with maximum neck rotation. Successively greater moments are placed on the discs with each level of the cervical spine down to C7-T1 experiencing the greatest torque.

\subsection{Muscle forces}

Figure 12 shows the maximum force developed in each of the muscle elements on the left side of the neck during the $15 \mathrm{~g}$ frontal impact. Because of the midsagittal symmetry of the neck model and the direction of the frontal impact being solely in the $x-z$ plane the forces in the left and right muscle elements are identical. All the muscles play a role in resisting the forward flexion of the head with the semispinalis capitis and cervicis, splenius capitis, 

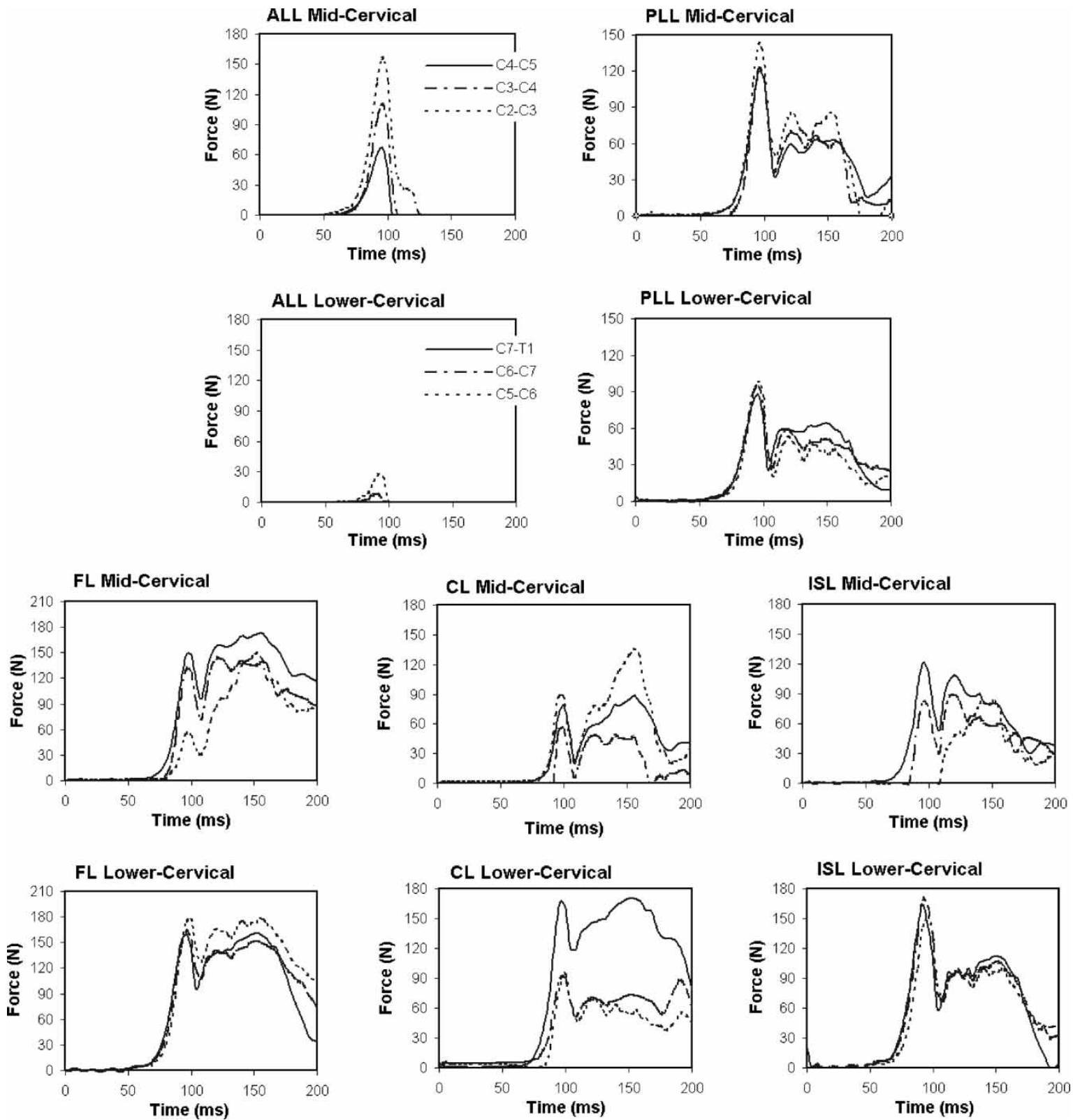

Fig. 9 Forces in the ligaments of the lower cervical spine during the $200 \mathrm{~ms}, 15 \mathrm{~g}$ frontal impact. The forces in the left CL ligaments are shown
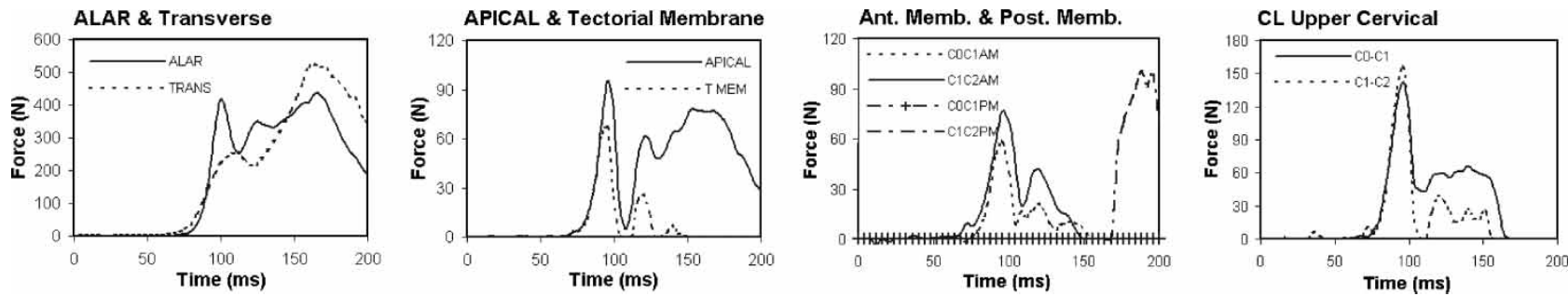

Fig. 10 Forces in the ligaments of the upper cervical spine during the $200 \mathrm{~ms}, 15 \mathrm{~g}$ frontal impact. The forces in the left Alar and CL are shown while the combined forces of the left and right transverse ligaments are presented as this is treated as a single ligament 

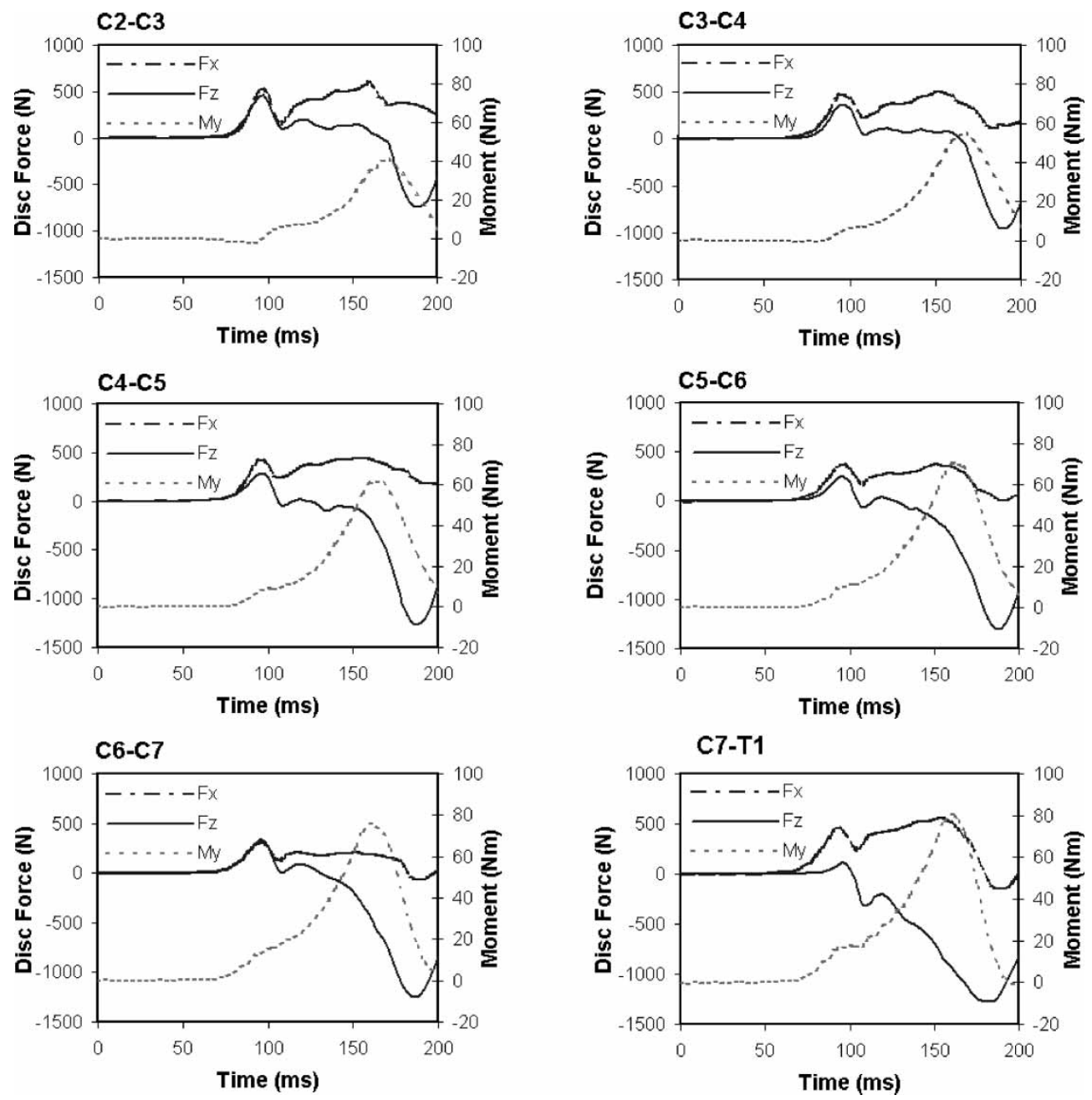

Fig. 11 Intervertebral disc loads over the $200 \mathrm{~ms}$ frontal impact

trapezius, levator scapulae, and the suboccipital muscle providing the most resistance to the forward motion of the head and neck. The large forces in the scalenus and sternocleidomastoid muscles are developed following the maximum rotation of the neck as the head and neck begin to rebound. The total combined muscle force acting on the head and cervical spine over the duration of the $200 \mathrm{~ms}$ impact is shown in Fig. 13. It can be seen that significant muscle force is built up following the $75 \mathrm{~ms}$ onset delay reaching an initial peak at the point of maximum neck excursion $(\sim 100 \mathrm{~ms})$, the force then drops off as the majority of muscles are rapidly shortened as the head is pulled back by the shortening of the neck because of the large initial tension in the discs and ligaments (see 'neck length' in Fig. 5(c) and ligament and disc forces in Figs 9 to 11). Muscle force then increases as the head and neck flex forward lengthening the muscles, a second peak where maximum muscle force is reached is seen at around $160 \mathrm{~ms}$ at the point of maximum neck flexion. As the head and neck begin to rebound the muscle force tails off slightly as the majority of muscles on the posterior of the neck begin to shorten, however, at this point forces begin to develop in the sternocleidomastoid and scalenus muscles as they try to resist the return motion of the head and neck.

\section{REAR-END IMPACT SIMULATION}

\subsection{Response of ligamentous cervical spine}

The overall response of the ligamentous spine model to the $8.5 \mathrm{~g}$ trauma class is shown schematically in Fig. 14. Figure 15 shows the head rotation and head vertical and horizontal translation for the $8.5 \mathrm{~g}$ trauma class compared with the experimental results of Grauer et al. [15]. The model shows a similar response to the cadaveric spine specimen, however, the maximum rotation of the head is around $10^{\circ}$ greater in the model. Following the maximum rotation and maximum posterior translation of the head the model rebounds slightly slower than is seen with the spine specimen. The vertical displacement of the head with respect to the torso is in good agreement with the 

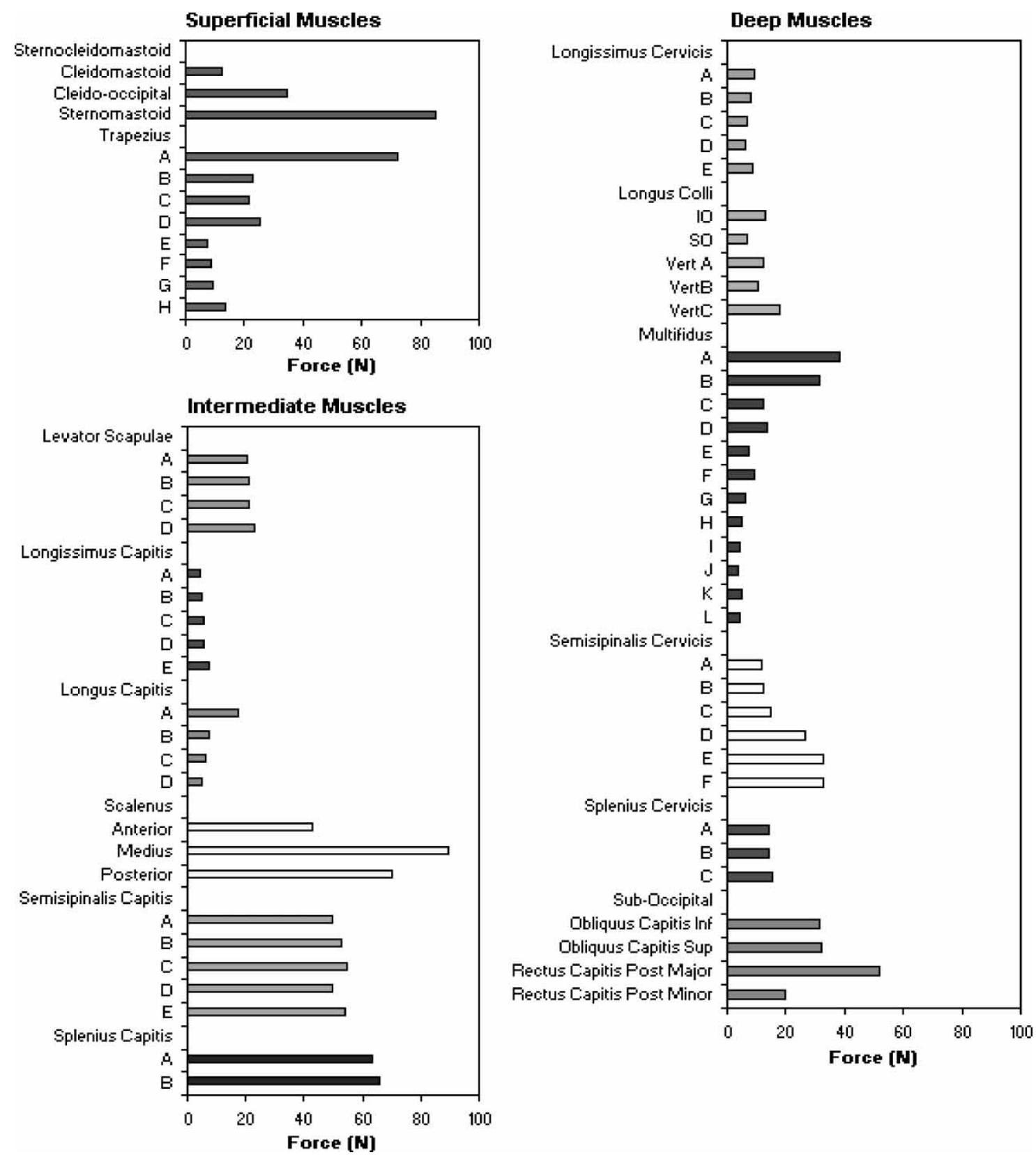

Fig. 12 Combined total muscles force acting on the head and neck over the duration of the $15 \mathrm{~g}$ frontal impact

experimental results reaching a peak of around $5 \mathrm{~cm}$ below the initial height.

During the acceleration portion of the whiplash the head translates posteriorly and inferiorly with respect to $\mathrm{T} 1$ and the spine extends. Over the $50-75 \mathrm{~ms}$ time period the development of the characteristic S-shaped curvature of the cervical spine is observed. It can be seen from the vertebral rotation graphs shown in Fig. 16 that during this time period the upper levels of the spine (C0-C3) are flexed whereas the lower levels (C5-T1) are extended as was seen in the experimental results. The $75-100 \mathrm{~ms}$ time period sees the upper vertebrae of the model change from flexion to extension as the whole model becomes more and more extended into a C-shaped curvature as also observed in the isolated spine experiments. Maximum extension of the head and neck is reached at $\sim 125 \mathrm{~ms}$, slightly later than the experimental results. In the later stages of trauma the head returns towards its initial starting configuration.

Figures 17 and 18 compare the maximum intervertebral rotations of the model for the four trauma classes simulated with those reported for the spine specimens. Figure 17 shows the maximum flexion and extension of the upper three levels of the cervical spine. The graphs show that although the upper levels are initially forced into flexion in the model, the levels of flexion experienced are noticeably smaller 


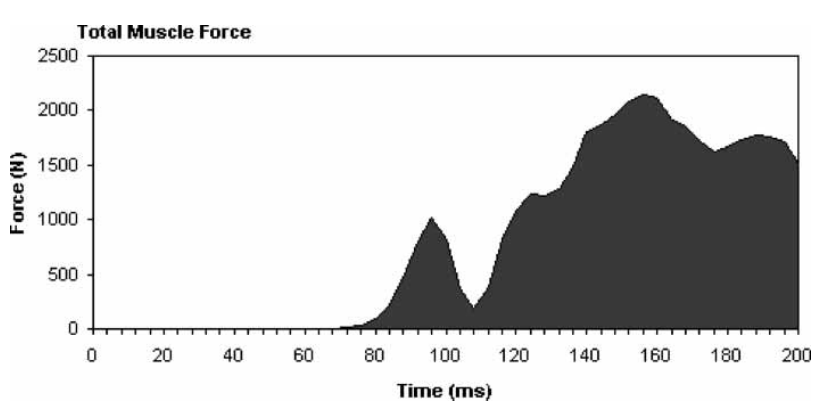

Fig. 13 Maximum muscle force developed in each of the muscle elements on the left side of the neck for active response to $15 \mathrm{~g}$ frontal impact

than the isolated spine specimens indicating that perhaps the model is too stiff in flexion in these areas. The levels of extension experienced in the later stages of impact agree more favourably with the experimental data. Figure 18 shows the maximum intervertebral extension rotations experienced by the lower five levels of the spine model. Although small levels of flexion were experienced $\left(<0.3^{\circ}\right.$ at all levels) for some of the lower segments in the early stages of impact they are not presented here as they are thought small enough to be insignificant to the overall response. Comparable levels of extension are seen at each level for each trauma class; noticeable differences can be seen at $\mathrm{C} 3-\mathrm{C} 4$ for $6.5 \mathrm{~g}$ and at C6-C7 for both $4.5 \mathrm{~g}$ and $8.5 \mathrm{~g}$ impacts (no experimental) data was reported for $\mathrm{C} 7-\mathrm{T} 1$ at $4.5 \mathrm{~g}$. Generally, level C6-C7 appears to be too stiff when compared with the experimental results. As would be expected the response of the model shows increasing levels of maximum flexion and extension for the increasing severity of impact; this pattern however, is not clear in the experimental results of the cadaveric ligamentous spine specimens.

\subsection{Effect of musculature on head-neck motion}

Figure 19 depicts the head-neck response with active musculature over the $250 \mathrm{~ms} 8.5 \mathrm{~g}$ rear-end impact simulation. A similar overall response is obtained as was seen for the ligamentous cervical spine model. It can be seen from the force vectors how muscle force is developed in the anterior muscle groups of the neck in response to the initial retraction motion of the head with respect to $\mathrm{T} 1$, and continues to increase as the head and neck extend. Forces are developed in the posterior muscle groups following the rebound of the head. Figure 20 compares the head and neck rotation of the passive and active spine model. Neck rotation is the rotation of a point-topoint line connecting the centre of $\mathrm{T} 1$ vertebral body with the centre of the occipital condyles. This was used in the validation as it was one of the corridors developed from the NBDL data. It shows how much the head lags behind the neck. Very little difference is seen between the two responses, both reaching the same level of head extension at the same time. Peak neck rotation is reduced slightly with quicker rebound of the neck observed with muscle tensioning.

Figure 21 compares the peak forces and moments developed in the intervertebral discs for the passive, active, and ligamentous cervical spine model. With active musculature the level of compression in the discs is significantly increased at all levels except for C7-T1. For the upper four intervertebral discs the peak compressive force is over double that is seen in

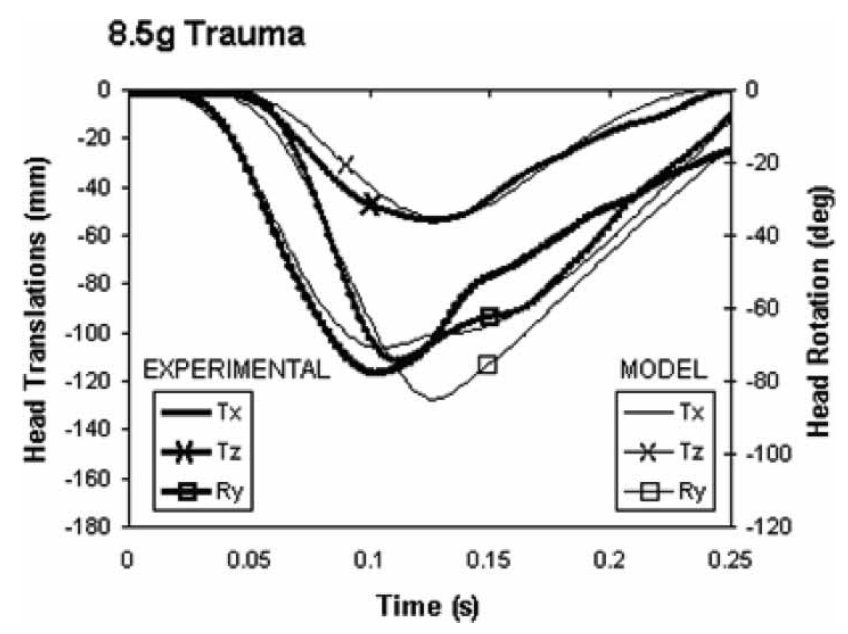

Fig. 15 Head rotation, and translations with respect to T1 versus time. Simulation of $8.5 g$ bench-top trauma test using the ligamentous head-neck model compared with experimental results (shown in respective faded colours). Negative values indicate posterior $(-x)$ and inferior $(-z)$ translations and extension $(-y)$ rotations

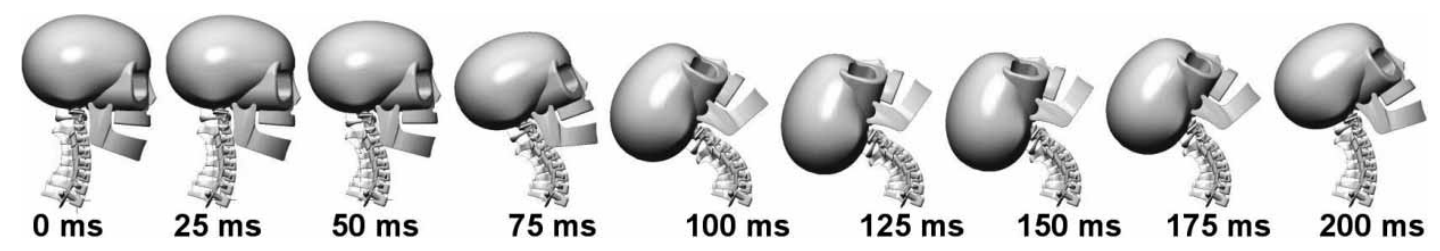

Fig. 14 Kinematics of ligamentous head-neck model for $8.5 \mathrm{~g}$ rear-end impact trauma at 25 ms time intervals 


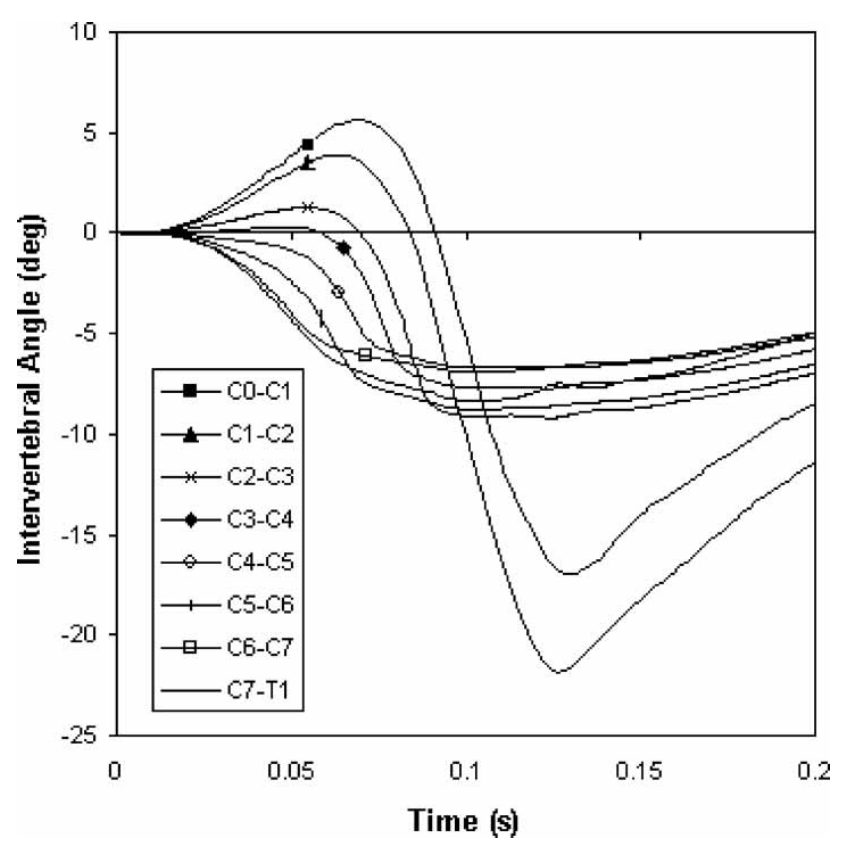

Fig. 16 Intervertebral rotations at each level of the head-neck model in response to the applied $8.5 \mathrm{~g}$ acceleration pulse at T1. Positive rotations indicate flexion response whereas negative values indicate extension

the ligamentous model. The peak tensile forces in the lower cervical spine are increased with passive muscle properties, with active musculature only the $\mathrm{C} 2-\mathrm{C} 3$ disc experiences any level of tension with a peak value similar to the ligamentous spine model. Shear forces

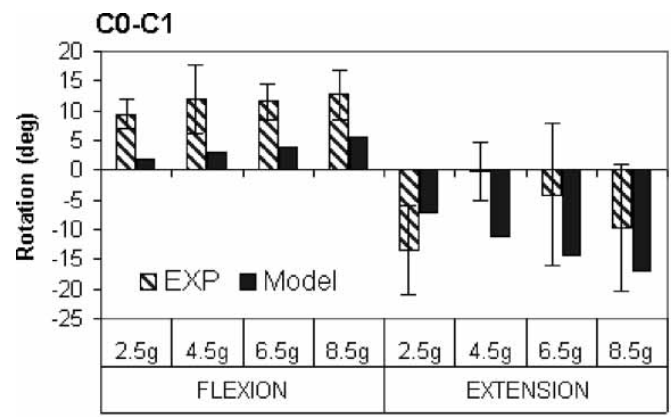

in the disc are generally decreased with active muscles whereas the passive model shows increases in peak posterior shear at all levels. The peak extension moment on the discs is fairly similar for the upper four levels of the active and passive model, both being around 30 per cent higher than with the ligamentous model. For the lower two levels, C6-T1, the maximum torque on the discs with active musculature is about the same as experienced by the ligamentous model while the passive model remains around 15 per cent higher.

Because of the increased compressive forces in the neck generated by the active muscle response the peak forces experienced by the facet joints are significantly increased. Figure 22 shows the maximum facet force on the left articular facets and also the peak force on the dens facet. The passive response of muscles has little effect on the peak loads of the lower cervical spine facets showing similar values to those seen with the ligamentous model. The upper cervical spine facets have greatly increased maximum load with the inclusion of muscles to the model both with active and passive response.

Small variations were seen in peak ligament forces with the inclusion of active and passive musculature. Table 1 presents the maximum ligament forces for the active muscle simulation as percentages of dynamic failure load. It can be seen that the alar ligaments reach 100 per cent of their predicted dynamic failure load indicating their vulnerability in rear-end impact. The anterior longitudinal ligaments
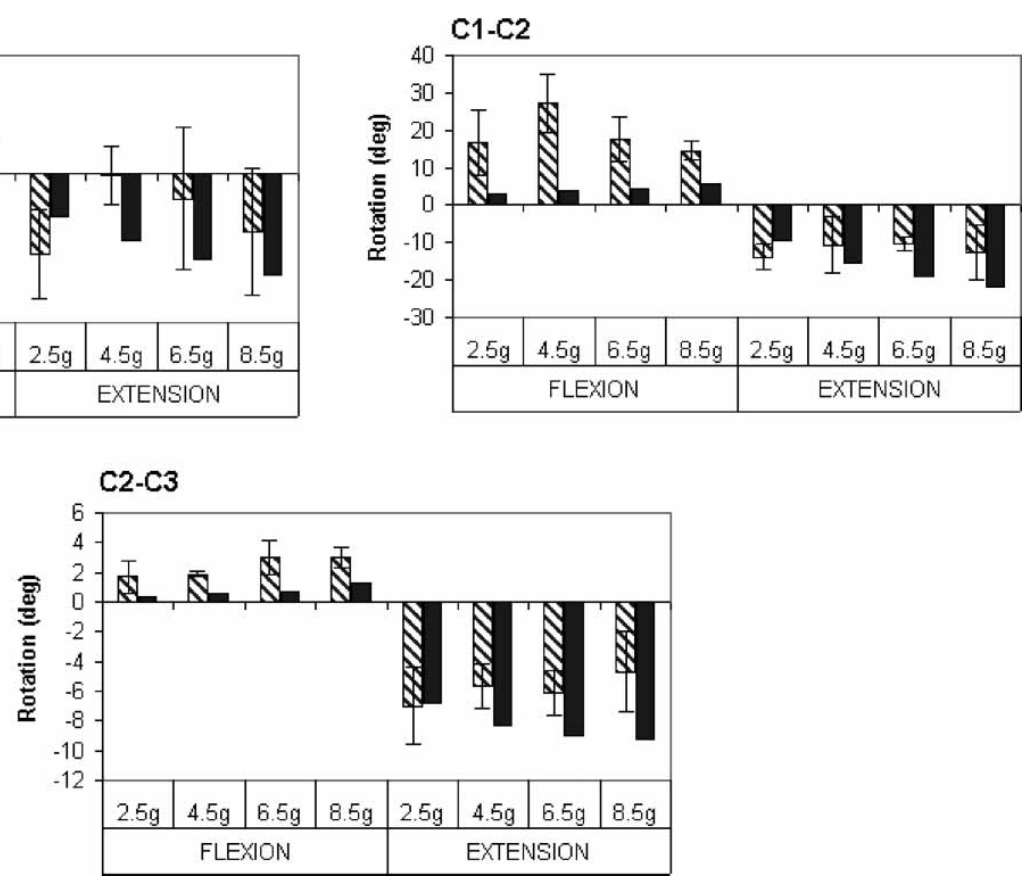

Fig. 17 Maximum intervertebral angles achieved during the four whiplash trauma classes for the upper three motion segments of the ligamentous cervical spine model, shown against the average \pm SD of the experimental data 

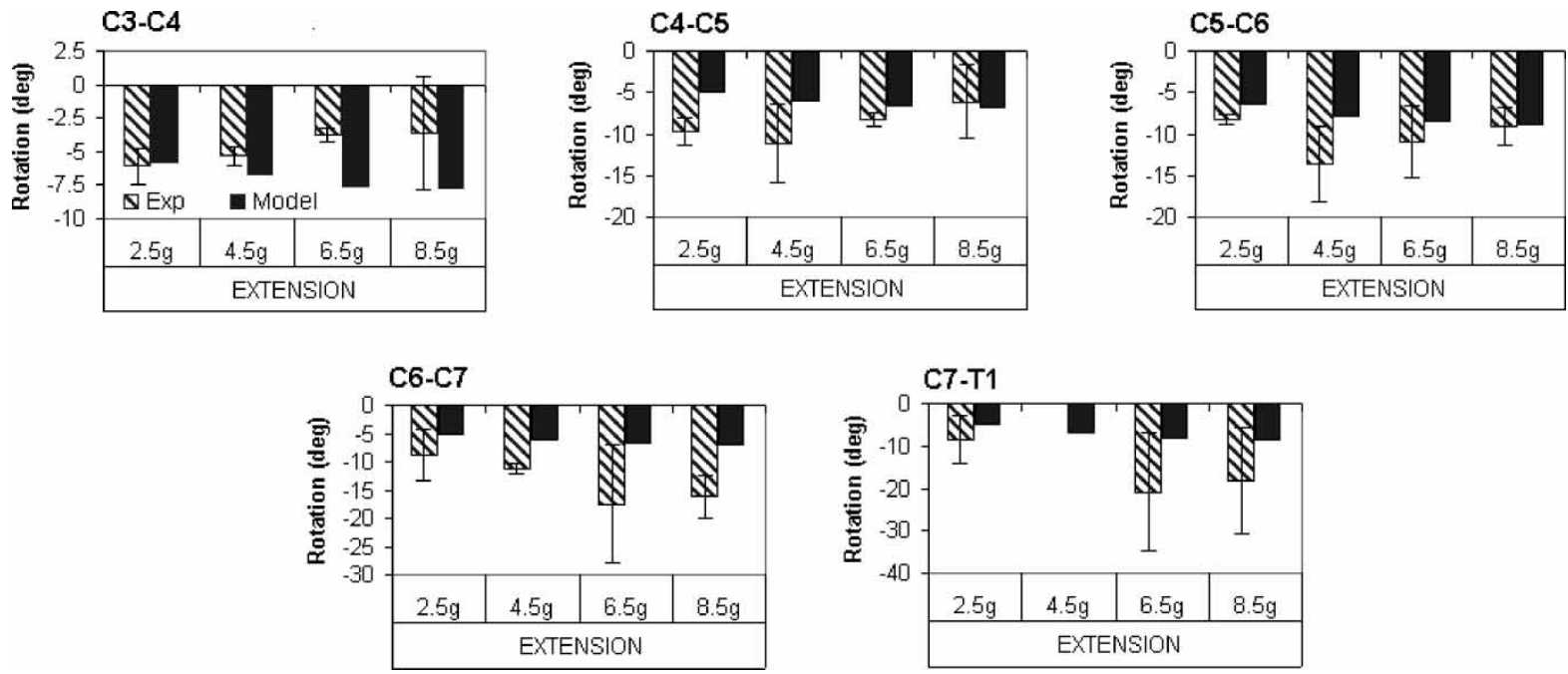

Fig. 18 Maximum intervertebral angles achieved during the four whiplash trauma classes for the lower five motion segments of the ligamentous cervical spine model, shown against the average \pm SD of the experimental data. The lower segments of the model did not experience significant levels of flexion during any of the trauma classes, so only maximum extension is shown
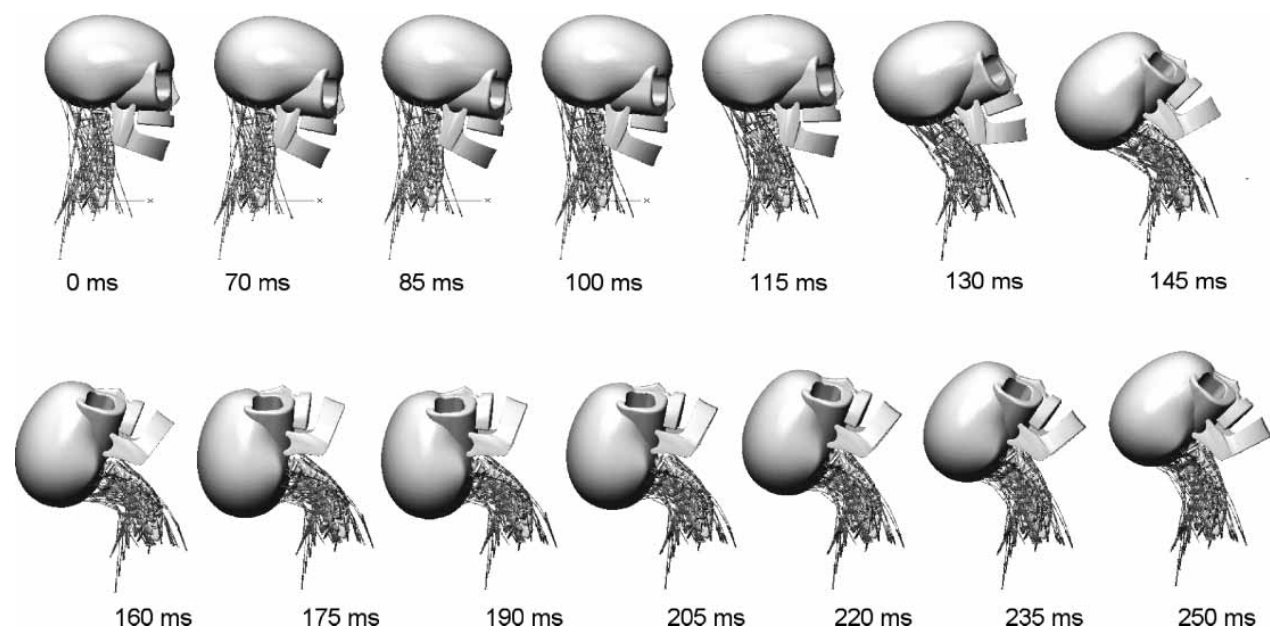

Fig. 19 Time history of the head and neck response to $8.5 \mathrm{~g}$ rear-end impact with 100 per cent active musculature
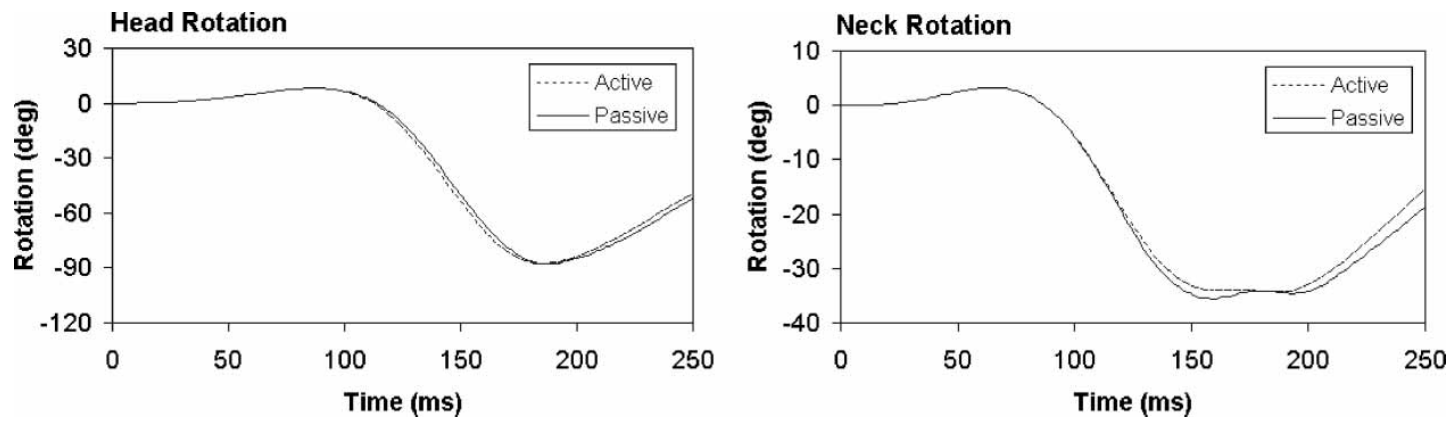

Fig. 20 Head and neck rotation in response to the $8.5 \mathrm{~g}$ rear-end impact simulation with active and passive muscle behaviour 

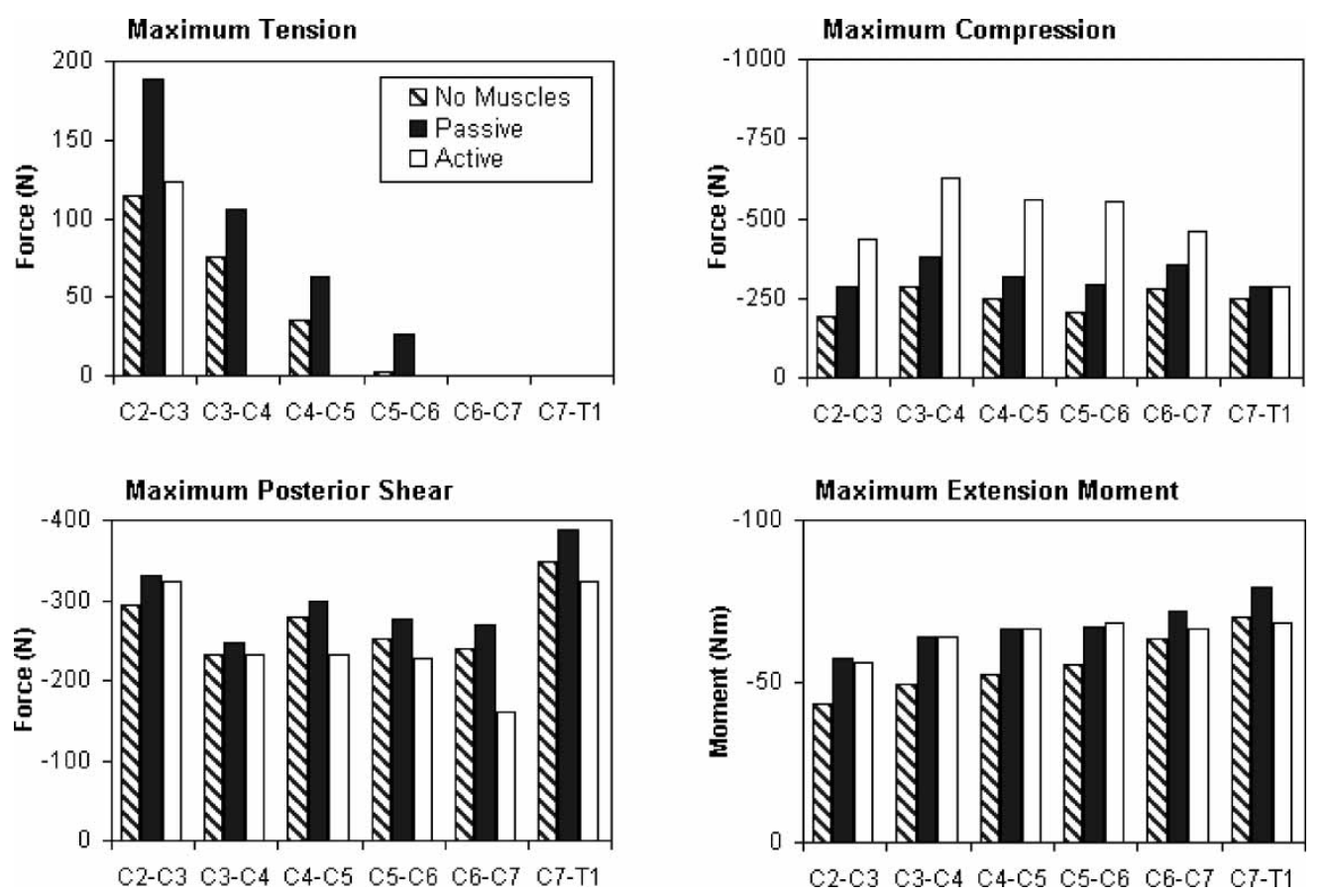

Fig. 21 Comparison of maximum disc forces and moments for the head-neck model in response to $8.5 \mathrm{~g}$ acceleration impact with and without the influence of active and passive musculature

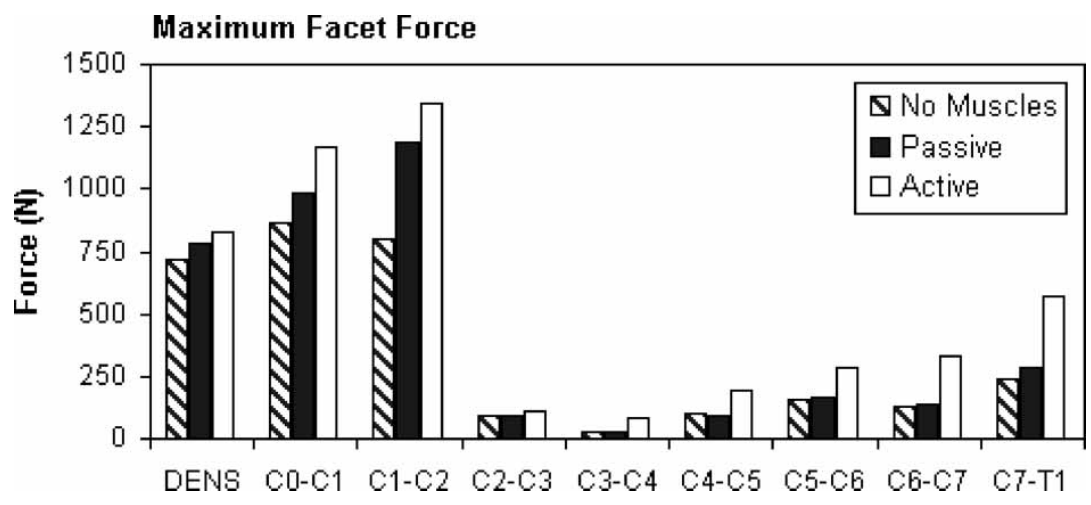

Fig. 22 Comparison of maximum facet forces for the head-neck model in response to $8.5 \mathrm{~g}$ acceleration impact with and without the influence of active and passive musculature

Table 1 Peak ligament forces as percentage of dynamic failure force for $8.5 \mathrm{~g}$ rear-end impact simulation with active musculature

\begin{tabular}{|c|c|c|c|c|c|c|c|c|c|}
\hline & $\mathrm{C} 0-\mathrm{C} 2$ & $\mathrm{C} 0-\mathrm{C} 1$ & $\mathrm{C} 1-\mathrm{C} 2$ & C2-C3 & C3-C4 & C4-C5 & C5-C6 & C6-C7 & $\mathrm{C} 7-\mathrm{T} 1$ \\
\hline \multicolumn{10}{|c|}{ Ligament } \\
\hline ALL & & & & 56 & 30 & 23 & 14 & 10 & 15 \\
\hline PLL & & & & 6 & 3 & 1 & 1 & 1 & 1 \\
\hline FL & & & & 15 & 7 & 4 & 3 & 3 & 3 \\
\hline ISL & & & & 25 & 16 & 8 & 11 & 15 & 16 \\
\hline CL & & 21 & 28 & 6 & 7 & 5 & 7 & 4 & 1 \\
\hline Alar & 100 & & & & & & & & \\
\hline Apical & 43 & & & & & & & & \\
\hline AM & & 10 & 42 & & & & & & \\
\hline PM & & 16 & 21 & & & & & & \\
\hline $\mathrm{TL}$ & & & 6 & & & & & & \\
\hline TM & 20 & & & & & & & & \\
\hline
\end{tabular}

Dynamic failure force calculated as 2.7 times static failure force of each ligament as reported in references [17] to [19]. 
also reach relatively high loads with the ALL of C2-C3 being over 50 per cent the dynamic failure force.

\section{DISCUSSION}

From the analysis of frontal and lateral impact, it would appear that the inclusion of active muscle behaviour in the model is essential in more accurately predicting the head-neck response to impact since the results show closest agreement with the response corridors. The passive response is more likely to represent the response of cadaveric specimens showing greater head rotations resulting in 'overtipping' of the head as head rotation exceeds neck rotation, where the influence of active musculature is absent [20]. For frontal impact the linear and angular accelerations of the head are in reasonable agreement with the experimental data with little variation between the active and passive response. The passive muscle properties lead to the trajectory and rotation of the head exceeding the corridors as well as the neck length in the later stages of impact. Muscle tensioning appears to have little influence on the rotation of the neck with both the passive and active response being similar, both resulting in reasonable levels of neck rotation, but reaching a maximum slightly earlier than seen with the volunteers. Head lag is clearly demonstrated by the model with both passive and active behaviour resulting in nearly identical rotation between the head and neck over the first half of the impact duration. However, the passive response deviates from the corridors significantly towards the end of the impact duration as head rotation increases compared to that of the active model where head rotation is reduced due to muscle tensioning.

For lateral impact satisfactory agreement is observed between the active model and the response corridors, with muscle tensioning having a greater effect on the head-neck motion than seen with the frontal impact. The influence of muscle activation leads to significantly reduced head rotation in the impact direction as well as reduced head and occipital condyle trajectories, although they still exceed the response corridors towards the end of the impact. The linear and angular accelerations of the head are also improved because of muscle tensioning. In comparison with the volunteer data the model appears to be too flexible in lateral bending, this is likely because of the linear stiffness of the intervertebral discs in this direction, resulting in too large displacements at high loads.

The analysis of local loads in the soft-tissue components of the model demonstrates the model's potential to predict injury to the cervical spine. The ligament forces show a clear peak in force quite early in the impact in conjunction with the peak head acceleration. For the majority of the cervical ligaments this peak also corresponds to the maximum load experienced over the course of the $200 \mathrm{~ms}$ acceleration pulse. Although for the severity of impact simulated, no injury is expected, it is reasonable to assume that in impacts of greater severity it will be at this initial peak in force where injury would occur. The intervertebral discs experience a similar peak in force at around $100 \mathrm{~ms}$ as the neck reaches maximum excursion under a combination of tension and axial shear. In the later stages of the impact significant compressive forces and torque around the $y$-axis are developed in the discs. The compressive loads developed in the intervertebral discs never exceed 50 per cent of reported failure forces in this mode of loading [21]. However, it is unclear if the combination of anterior shear and compression would cause damage. Dynamic properties of the intervertebral discs characterizing the response to large loads and failure limits in all directions of loading need to be established for both modelling and validation purposes.

Qualitatively the model successfully reproduces the characteristic motion of the head and neck when subjected to rear-end impact. From the onset of T1 acceleration shear forces are built up in the discs due to the forward movement of $\mathrm{T} 1$ relative to the head. The shear forces are transferred from the lowest level upward through the soft-tissue components of the neck model, creating an extension moment between the lower vertebrae. The differential movement between the head and T1 causes initial flexion in the upper joints as the head translates backward, without rotation, relative to $\mathrm{T} 1$. The formation of this 'S' shaped curvature of the neck with flexion of the upper and extension of the lower joints is typical of 'whiplash' motion and is a phenomenon that does not occur under normal physiological movements of the head. Following the development of the ' $S$ ' curve, the neck then goes into extension at all levels as the head rotates rearward to a point of maximum extension before rebounding towards its initial position.

For the most severe impact simulated, the resulting head rotation and displacement agree reasonably well with the experimental results, however, the maximum extension of the head is greater than seen with the spine specimens. The maximum intervertebral rotations are shown to increase with increasing impact severity and agree reasonably well with reported values.

Following the validation of the ligamentous spine model the cervical musculature was added back to the model to study the effects of active and passive muscle response on the head-neck motion, and internal loads when subjected to the most severe whiplash acceleration. Little difference was observed between the active and passive response in terms of head 
and neck rotation, however, muscle tensioning significantly altered the internal loads in the soft-tissue components for the activation scenario simulated. It would appear that although the anterior muscle groups of the neck (flexors) are able to generate significant force in reaction to the retraction phase of the head relative to the torso their attachments to the head and neck and subsequent lines of action make them not well suited to resisting this translatory motion, instead generating increasing levels of compression in the neck. Peak disc compression forces and peak facet forces are dramatically increased with the inclusion of muscle tensioning while the levels of posterior shear in the discs are reduced.

Analysis of peak ligament forces shows the alar ligaments to be at risk of injury in the $8.5 \mathrm{~g}$ rear-end impact, however, this peak in force occurs in conjunction with maximum extension of the head and so would most likely be prevented by the use of a head restraint as would the peak forces for the majority of the upper cervical spine ligaments. In the lower cervical spine the anterior longitudinal ligaments reach a peak in force prior to the development of maximum head and neck extension due to the local extension of the lower vertebrae in the formation of the ' $\mathrm{S}$ ' shaped curvature of the neck. Ivancic et al. [22] have also found the anterior longitudinal ligaments of the lower cervical spine to be at greatest risk when simulating whiplash using isolated cervical spine specimens with simulated muscle forces. The inclusion of a head restraint to the model simulation would identify if these ligament forces can be prevented and would help to determine the required positioning of a head restraint to best prevent excessive loads that develop in the soft-tissue components.

\section{ACKNOWLEDGEMENT}

The authors gratefully acknowledge the $\mathrm{PhD}$ studentship received from the EPSRC (Engineering and Physical Sciences Council) of the United Kingdom for this research.

\section{REFERENCES}

1 van Lopik, D. W. and Acar, M. Development of a multibody computational model of human head and neck. Proc. IMechE, Park K. J. Multi-body Dynamics, 2007, 221(K2), 175-197 (this issue).

2 Mitiguy, P. C. and Banerjee, A. K. Constraint force algorithm for formulating equations of motion. In Proceedings of the First Asian Conference on Multibody Dynamics (Eds N. Shimizu et al.), ACMD '02, Iwaki, Fukushima, Japan, The Japan Society of Mechanical Engineering, 31 July-2 August 2002, pp. 606-608.

3 Dauvilliers, F., Bendjellal, F., Weiss, M., Lavaste, F., and Tarriere, C. Development of a finite element model of the neck. In Proceedings of the 38th Stapp Car Crash Conference, 1994, pp. 77-91. Society of Automotive Engineers, SAE paper 942210.

4 De Jager, M. K. J. Mathematical head-neck models for acceleration impacts. PhD Thesis, Technical University of Eindhoven, 1996.

5 Van der Horst, M. J., Thunnissen, J. G. M., Happee, R., Van Haastar, R. M. H. P., and Wismans, J. S. H. M. The influence of muscle activity on the head-neck response during impact. SAE Trans., 1997, 106(2), 4003-4023.

6 Van der Horst, M. J. Human head neck response in frontal, lateral and rear end impact loading-modelling and validation. $\mathrm{PhD}$ Thesis, Technical University of Eindhoven, 2002.

7 Jost, R. and Nurick, G. N. Development of a finite element model of the human neck subject to high g-level lateral deceleration. Int. J. Crashworthiness, 2000, 5(3), 259-269.

8 Thor. Biomechanical response requirements of the THOR NHTSA advanced frontal dummy (revision 2001.02). Trauma assessment device development program, 2001, available from http://www-nrd.nhtsa.dot. gov/departments/nrd-51/THORAdv/THORAdv.htm.

9 Thunnissen, J., Wismans, J., Ewing, C. L., and Thomas, D. J. Human volunteer head-neck response in frontal flexion: a new analysis. In Proceedings of the 39th STAPP Car Crash Conference, 1995, pp. 439-460, Society of Automotive Engineers, SAE paper 952721.

10 Wisman, J., Van Oorshot, E., and Woltring, H. J. Omni-directional human head-neck response. In 30th Stapp Car Crash Proceedings, 1986, pp. 313-331, Society of Automotive Engineers, SAE paper 861893.

11 Panjabi, M. M., Cholewicki, J., Nibu, K., Babt, L. B., and Dvorak, J. Simulation of whiplash trauma using whole cervical spine specimens. Spine, 1998, 23(1), 17-24.

12 Panjabi, M. M., Cholewicki, J., Nibu, K., Grauer, J. N., Babt, L. B., and Dvorak, J. Mechanism of whiplash injury. Clin. Biomech., 1998, 13, 239-249.

13 Panjabi, M. M., Pearson, A. M., Ito, S., Ivancic, P. C., and Wang, J.-L. Cervical spine curvature during simulated whiplash. Clin. Biomech., 2004, 19, 1-9.

14 Grauer, J. N, Panjabi, M. M., Cholewicki, J., Nibu, K., and Dvorak, J. Whiplash produces an S-shaped curvature of the neck with hyperextension at lower levels. Spine, 1997, 22(21), 2489-2494.

15 Siegmund, G. P. and Brault, J. R. Role of cervical muscles during whiplash. In Frontiers in whiplash trauma, clinical and biomechanical (Eds N. Yoganandan and F. A. Pintar), 2000, pp. 295-320 (IOS Press, Amsterdam).

16 Raynak, G. C. and Ching, R. P. Dynamic sled tuning for benchtop whiplash simulation. In Frontiers in whiplash trauma, clinical and biomechanical (Eds N. Yoganandan and F. A. Pintar), 2000, pp. 186-197 (IOS Press, Amsterdam).

17 Myklebust, J. B., Pintar, F., Yoganandan, N., Cusick, J. F., Maiman, D., Myers, T. J., and Sances, A. Tensile strength of spinal ligaments. Spine, 1988, 13(5), 526-531.

18 Yoganandan, N., Pintar, F. A., Butler, J., Reinartz, J., Sances, A., and Larson, S. J. Dynamic response of human cervical spine ligaments. Spine, 1989, 14(10), 1102-1109. 
19 Yoganandan, N., Kumaresan, S., and Pintar, F. A. Geometric and mechanical properties of human cervical spine ligaments. J. Biomech. Eng., 2000, 122, 623-629.

20 Wisman, J., Philippens, M., Van Oorshot, E., Kallieris, D., and Mattern, R. Comparison of human volunteer and cadaver head-neck response in frontal flexion. In 31th Stapp Car Crash Proceedings, 1987, pp. 1-11, Society of Automotive Engineers, SAE paper 872194.

21 Yamada, H. Strength of biological materials, 1970 (Ed F. G. Evans) (Williams and Wilkins, Baltimore).

22 Ivancic, P. C., Pearson, A. M., Panjabi, M. M., and Ito, S. Injury of the anterior longitudinal ligament during whiplash simulation. Eur. Spine J., 2004, 13(1), 61-68. 
